\title{
Excitatory Postrhinal Projections to Principal Cells in the Medial Entorhinal Cortex
}

\author{
Noriko Koganezawa, Ragnhild Gisetstad, Ellen Husby, Thanh P. Doan, and Menno P. Witter \\ Kavli Institute for Systems Neuroscience and Centre for Neural Computation, Norwegian University of Science and Technology, NO-7491 Trondheim, \\ Norway
}

The postrhinal cortex (POR) provides substantial input to the entorhinal cortex, mainly targeting superficial layers of the medial entorhinal cortex (MEC). Major inputs to POR originate in the visual and parietal cortex, thus providing neurons in MEC with a subset of cortical information relevant to their spatial firing properties. The POR takes a position that is comparable with that of the perirhinal cortex (PER) with regard to the lateral entorhinal cortex (LEC). Neurons in LEC and MEC show different functional properties likely reflecting differences in their respective inputs. Projections from PER to LEC exert a main inhibitory influence, which may relate to the sparse object-selective firing in LEC. In view of the continuous, spatially modulated firing properties of principal neurons in MEC, we tested in rats the hypothesis that projections from POR to MEC are functionally different from the PER-to-LEC counterpart in providing an excitatory drive to MEC. Our combined confocal and quantitative electron-microscopic observations indicated that POR projections target mainly principal cells in MEC, including neurons that project to the hippocampus. The ultrastructure of the majority of the synapses indicated that they are excitatory. Voltage-sensitive dye imaging in sagittal slices confirmed this morphologically derived conclusion, showing that the MEC network always responded with an overall depolarization, indicative for net excitatory transmission. In vitro single-cell recordings from principal cells showed only excitatory responses upon POR stimulation. These results show that POR provides an excitatory projection to MEC, differing fundamentally from the inhibitory projection of PER to LEC.

Key words: excitation; lateral entorhinal cortex; memory; parahippocampal region; perirhinal cortex

\section{Significance Statement}

The study provides anatomical and electrophysiological data indicating that projections from the postrhinal cortex to the medial entorhinal cortex (MEC) are excitatory, providing the substrate for high probability of information transfer and thus a continuous input stream into MEC. This is a relevant component of the spatial navigational network found in MEC. The findings are in contrast to previous reports on the parallel pathway from the perirhinal cortex to the lateral entorhinal cortex. This pathway, characterized by a preponderance of inhibitory connections, mediates information transfer with a low probability, likely related to the discontinuous object-related firing of neurons in the lateral entorhinal cortex.

\section{Introduction}

The postrhinal cortex (POR), together with the perirhinal cortex (PER), mediate important projections from cortical domains

\footnotetext{
Received Feb. 17, 2015; revised 0ct. 13, 2015; accepted 0ct. 23, 2015.

Author contributions: N.K. and M.P.W. designed research; N.K., R.G., E.H., and T.P.D. performed research; N.K., R.G., E.H., T.P.D., and M.P.W. analyzed data; N.K. and M.P.W. wrote the paper.

This work was supported by the Kavli Foundation, European Union 7th framework (Spacebrain Grant 200873), Centre of Excellence (Grant 145993), and Norwegian Research Council equipment grant (181676) and research grant (191929). We thank our colleagues at the EM-core facility of Norwegian University of Science and Technology, enabling us to perform the EM part of the study; and Rafal Czajkovski and Gunhild Fjeld for help with the confocal analysis.

The authors declare no competing financial interests.

Correspondence should be addressed to Dr. Menno P. Witter, Kavli Institute for Systems Neuroscience and Centre for Neural Computation, Medical-Technical Research Center, Postboks 8905, N0-7491 Trondheim, Norway. E-mail: menno.witter@ntnu.no.

N. Koganezawa's present address: Department of Neurobiology and Behavior, Gunma University Graduate School of Medicine, 371-8511 Maebashi, Japan.
}

into the entorhinal cortex (EC), which in turn is the main entry point to the hippocampal formation (Eichenbaum et al., 2007; Ranganath and Ritchey, 2012; Cappaert et al., 2014). Whereas PER receives inputs from all sensory modalities, inputs to POR originate in visual and visuospatial regions (Burwell and Amaral, 1998a, b; Burwell, 2000; Agster and Burwell, 2009). These two main input streams to EC show a strikingly different distribution such that PER mainly innervates the lateral entorhinal cortex (LEC), whereas the projections from POR preferentially innervate the medial entorhinal cortex (MEC) (Naber et al., 1997; Burwell and Amaral, 1998b; Witter et al., 2000; Kerr et al., 2007).

In line with their inputs, PER and POR are functionally different. PER is critical to the representation of objects, and neu- 
rons in PER of the rat respond selectively to objects and convey information about the familiarity of the objects (Zhu and Brown, 1995; Zhu et al., 1995). Firing of neurons in POR has been associated with the spatial arrangement of objects or the context (Burwell and Hafeman, 2003; Furtak et al., 2012), and lesions of POR in rats have been shown to impair coding of context and egocentric spatial relations between objects, but not object perception itself (Bucci et al., 2000, 2002; Gaffan et al., 2004; Norman and Eacott, 2005). Lesion studies point to functional differences between LEC and MEC, in line with the functional differences of PER and POR (Eichenbaum et al., 2007; Ranganath and Ritchey, 2012). Moreover, LEC neurons respond to individual items, such as odors, pictures of objects, or have a memory code for objects and previous locations of specific objects, but do not show strong spatial firing in the absence of objects (Zhu and Brown, 1995; Zhu et al., 1995; Young et al., 1997; Hargreaves et al., 2005; Deshmukh and Knierim, 2011; Yoganarasimha et al., 2011). In contrast, MEC contains a variety of spatially modulated cells, such as grid cells, border cells, and head direction cells (Hafting et al., 2005; Sargolini et al., 2006; Solstad et al., 2008), all likely representing elements of an allocentric spatial code (Zhang et al., 2014).

The organization of the PER-to-LEC pathway has been studied in some detail. Despite strong anatomical connectivity between PER and LEC, signal transmission from PER to LEC occurs with an extremely low probability, likely as the result of strong feedforward inhibition, mediated by excitatory PER projections terminating onto inhibitory LEC neurons, as well as long-range inhibitory PER projections to LEC (de Curtis and Paré, 2004; Pinto et al., 2006; Apergis-Schoute et al., 2007). This wall of inhibition, as it has been referred to, essentially blocks incoming information to reach the entorhinal network, unless a second input, either from cortex (Pelletier et al., 2004) or from the lateral nucleus of the amygdala (Kajiwara et al., 2003; Paz et al., 2006; Koganezawa et al., 2008), converges with the first one. The PERto-LEC transmission might thus be discontinuous, depending on coincidence detection, likely representing relevant changes in sensory input (de Curtis and Paré, 2004). In view of the overall comparable position of PER and POR in relation to LEC and MEC, respectively, one may assume that the signal transmission from POR to MEC is under a feedforward inhibitory control, comparable with that seen in the PER-to-LEC pathway. However, several theoretical accounts on the possible origin of spatially modulated cells in MEC assume a continuous excitatory input representing, for example, information about directionality or velocity (McNaughton et al., 2006; Bonnevie et al., 2013; Couey et al., 2013; Moser et al., 2014). Therefore, one may hypothesize that the POR-to-MEC pathway, in contrast to the PERto-LEC pathway, comprises mainly excitatory projections. Using anterograde tracing, electron and confocal microscopic analyses, voltage-sensitive dye imaging, and single-cell recordings, we showed the latter hypothesis to be correct.

\section{Materials and Methods}

Experimental protocols were approved by the Norwegian Animal Research Authority and were in accordance with the European Convention for the Protection of Vertebrate Animals used for Experimental and Other Scientific Purposes. The animals were kept in individual cages on a $12 \mathrm{~h} \mathrm{light/dark} \mathrm{cycle} \mathrm{under} \mathrm{standard} \mathrm{laboratory} \mathrm{conditions}\left(19^{\circ} \mathrm{C}-22^{\circ} \mathrm{C}\right.$, $50 \%-60 \%$ humidity) and had free access to food and water.

\section{Anatomical tracing studies}

Light microscopy. We used 12 male Sprague Dawley rats (Charles River) with a body weight between 200 and $220 \mathrm{~g}$. Surgeries for tracer injections and subsequent analyses were performed as described previously, with minor modifications (Kononenko and Witter, 2012; Czajkowski et al., 2013). Animals were anesthetized with a mixture of isoflurane and oxygen (3\% isoflurane; Intervet International) in an induction chamber. They were subsequently mounted in a stereotaxic frame (Kopf Instruments) while maintaining stable anesthesia (1.5\% isoflurane). Stereotaxic coordinates for tracer injections were derived from the rat brain atlas of Paxinos and Watson (2007) and adjusted for weight. Projections from POR to MEC were visualized by injecting $5 \%$ biotinylated dextran amine (BDA; 10,000 MW, D-1956; Invitrogen) in 0.125 M PBS, pH 7.4, through glass micropipettes with an outer tip diameter of 15-20 $\mu \mathrm{m}$. The pipettes were stereotaxically lowered into dorsal or ventral parts of POR. The tracer was injected by applying a positively pulsed DC current to the micropipette ( $6 \mu \mathrm{A}, 6 \mathrm{~s}$ on, $6 \mathrm{~s}$ off) for 10-20 min. Six of these 12 animals received an additional injection with the retrograde tracer Fast Blue (FB, $150 \mathrm{nl} ; 1 \%$ in PBS, Electron Microscopy Sciences-Chemie), through a 1 $\mu \mathrm{l}$ Hamilton syringe that was placed vertically in the center of the dorsal hippocampus, $\sim 4 \mathrm{~mm}$ behind bregma. We aimed to label entorhinal projecting neurons, without selectively aiming for any of the hippocampal subdivisions. All animals were given a dose of buprenorphine (temgesic, RB Pharmaceuticals, $0.05 \mathrm{mg} / \mathrm{kg}$, subcutaneously) to reduce postsurgical pain $30 \mathrm{~min}$ before the end of the surgery. Suturing the skin over the wound completed surgery.

After 7-14 d of survival, the rats received an overdose of equithesin (a mixture of chloral hydrate, magnesium sulfate, and sodium-pentobarbital; $11 \mathrm{mg} / \mathrm{kg}$ body weight i.p.; Sanofi Sante). They were subsequently transcardially perfused with $200 \mathrm{ml}$ of a fresh filtrated oxygenated Ringer's solution $\left(0.85 \% \mathrm{NaCl}, 0.025 \% \mathrm{KCl}, 0.02 \% \mathrm{NaHCO}_{3}, 4^{\circ} \mathrm{C}\right.$, brought to $\mathrm{pH} 6.9$ with $\mathrm{CO}_{2}$ ) followed by $200 \mathrm{ml} 4 \%$ filtrated freshly depolymerized PFA (1.04005; Merck) in PBS at $4^{\circ} \mathrm{C}$. Subsequently, the brain was removed from the skull and postfixed at $4^{\circ} \mathrm{C}$ in the same fixative. The postfixation and subsequent procedures differ for the two subsequent analyses.

Fluorescence microscopic analysis of POR projections. We used the six animals that received only an anterograde tracer injection in POR to study the distribution of anterograde labeling of projections to MEC. After a postfixation overnight, the brains were cut in the sagittal plane with a vibrating microtome (Leica, model VT1000S) with $50 \mu \mathrm{m}$ steps, and all sections were collected. Sections were rinsed $3 \times 10 \mathrm{~min}$ in PBS and then $3 \times 10 \mathrm{~min}$ in Tris-buffered saline with Triton (TBS-Tx; $50 \mathrm{~mm}$ Tris, $153 \mathrm{~mm} \mathrm{NaCl}, 2 \%$ Triton X-100), pH 8.0. The sections were incubated in streptavidin conjugated to either Alexa-488 (S-11223), or Alexa546 (S-11225) or Alexa-635 (S-32364; Invitrogen) in a 1:200 solution with TBS-Tx overnight at $4^{\circ} \mathrm{C}$. Next, the sections were rinsed $2 \times 5 \mathrm{~min}$ in Tris- $\mathrm{HCl}(50 \mathrm{~mm}$ Tris, $\mathrm{pH}$ set at 7.6 with $\mathrm{HCl})$ and subsequently mounted on glass slides from a $0.2 \%$ gelatin solution in Tris-HCl. After overnight drying, they were cleared in xylene and coverslipped with Entellan (1.07961; Merck). Sections were inspected with dark-field and fluorescence illumination at the appropriate excitation wavelengths (Zeiss Axio Imager M2), and digital images of the anterogradely labeled plexus in the entorhinal cortex were obtained, either using the microscope or an automated scanner (Zeiss Mirax Midi). All images selected for illustration purposes were saved as gray-level images of which the contrast and brightness were equalized using Adobe Photoshop CS5 (Adobe Systems).

Confocal analyses of postsynaptic targets. We used the six animals with injections in POR (anterograde tracer) and hippocampus (retrograde tracer) to analyze whether the postsynaptic neurons of POR inputs in MEC project to the hippocampus. The brains were postfixed for only $2 \mathrm{~h}$. Following a protocol described in detail previously (Czajkowski et al., 2013), alternating $100-/ 400-\mu \mathrm{m}$-thick sagittal slices were cut with a vibratome (Leica, model VT1000S; bath fluid 0.1 м PBS). The $100-\mu \mathrm{m}-$ thick sections were incubated overnight at $4^{\circ} \mathrm{C}$ with AlexaFluor-546conjugated streptavidin and used to ascertain maximal overlap between BDA-filled axonal terminals and retrogradely FB stained hippocampalprojecting neurons in MEC.

We used the $400-\mu \mathrm{m}$-thick sections adjacent to the $100 \mu \mathrm{m}$ sections where an overlap was found for subsequent intracellular injections. The $400 \mu \mathrm{m}$ slices were rinsed in PBS and transferred to a chamber mounted on a fluorescence microscope equipped with a PlanApo $20 \times, 1.0 \mathrm{NA}$ 
water dipping objective (Zeiss examiner D1), a micromanipulator (Luigs \& Neuman), and an iontophoretic injection device capable of delivering nA-currents (home-made appliance) (Buhl et al., 1989). Intracellular filling of randomly selected FB-labeled cells in layers II and III of MEC was achieved by impaling cell bodies with a $70-130 \mathrm{M} \Omega$ glass pipette (microelectrode-tip diameter in the $0.5-0.8 \mu \mathrm{m}$ range) containing a mixture of AlexaFluorTM 555 hydrazide and AlexaFluorTM 568 hydrazide (A-20501MP, A-10441; both Invitrogen; $10 \mathrm{~mm}$ in $200 \mathrm{~mm} \mathrm{KCl).}$ Negative current was applied to the micropipette ( $2 \mathrm{nA}, 500 \mathrm{~ms}$ on, 500 $\mathrm{ms}$ off) until filling was judged complete by inspection, when the finest details such as dendritic spines and thin distal branches of dendrites far away from the cell body became visible. After filling, the sections were transferred to $4 \%$ PFA and postfixed overnight. Next, the slices were washed in PBS, $3 \times 15$ min each, and subsequently immunostained. Sections were washed seven times 15 min each in $0.1 \mathrm{~m}$ PBS containing $1 \%$ Triton X-100 at room temperature, preincubated with PBS containing 5\% normal goat serum (NGS, X0907, DAKO) and 1\% Triton X-100 for 2-3 h, and subsequently incubated with AlexaFluor488-conjugated streptavidin (1: 300 in PBS, 5\% NGS, and 1\% Triton X-100) for $12 \mathrm{~h}$ in darkness at room temperature. Later, sections were washed in PBS $3 \times 15$ min each, dehydrated in ascending ethanol series $(50 \%, 70 \%, 90 \% 10 \mathrm{~min}$ each, twice in $100 \%, 10$ min each), permeabilized in a 1:1 mixture of $100 \%$ ethanol and methylsalicylate (M6752; Sigma-Aldrich) for $10 \mathrm{~min}$, cleared and mounted in methylsalicylate. Slides were stored at $4^{\circ} \mathrm{C}$ for up to 2 months.

Laser scanning microscopy, reconstructions, and 3D analysis. Confocal image stacks were taken from areas of interest where dendrites of the intracellularly filled cell overlapped with the POR axonal plexus (Zeiss CLM 510, Carl Zeiss) (for detailed imaging protocols, see Kononenko and Witter, 2012; Czajkowski et al., 2013). After acquisition, all image files were processed with Amira 4.1.2 software (TGS, Mercury Computer Systems). We used a custom-developed Amira plug-in for 3D reconstruction of dendritic trees and spines (Schmitt et al., 2004; Evers et al., 2005) and analyzed the distribution of potential synapses by identifying BDA-positive voxels within $300 \mathrm{~nm}$ from the dendritic surface, and expressed this proximity as a heat map. Finally, for each putative contact, the zoomed image was analyzed, and it was determined whether it adheres to previously established criteria of a presynaptic bouton (Wouterlood et al., 2008), being an axonal swelling having a diameter 3 times bigger than the preceding fiber.

Electron microscopy (EM). We used seven male Sprague Dawley rats for EM analysis. The animals received a unilateral injection of BDA in MEC as described above. The animals survived for $14 \mathrm{~d}$, were killed by an overdose of equithesin and transcardially perfused with $200 \mathrm{ml}$ of oxygenated cold Ringer's solution $(0.85 \% \mathrm{NaCl}, 0.025 \% \mathrm{KCl}, 0.02 \%$ $\mathrm{NaHCO}_{3}, \mathrm{pH} 6.9,4^{\circ} \mathrm{C}$ ) followed by $200 \mathrm{ml}$ of a mixture of freshly depolymerized $4 \%$ PFA and $0.1 \%$ glutaraldehyde (Merck) in PBS at $4^{\circ} \mathrm{C}$. Sagittal vibratome sections $(50 \mu \mathrm{m})$ were rinsed for $10 \mathrm{~min}$ in an ascending series of $10 \%, 15 \%$, and $20 \%$ DMSO in PBS $4^{\circ} \mathrm{C}$. The sections were quickly frozen in isopentane cooled by solid carbon dioxide and subsequently recovered and thawed. This freeze-and-thaw procedure was repeated twice to increase the permeability of the neurons to facilitate subsequent staining for biotin. Sections were subsequently rinsed $3 \times 20$ $\min$ in PBS $4^{\circ} \mathrm{C}$ and $2 \times 5 \mathrm{~min}$ in TBS ( $50 \mathrm{~mm}$ Tris, $153 \mathrm{~mm} \mathrm{NaCl}$ ), $\mathrm{pH}$ 7.6, $4^{\circ} \mathrm{C}$. The sections were incubated with avidin-biotin-peroxidase complex (Vectastain ABC kit Standard, PK-400) in TBS for $48 \mathrm{~h}$ at $4^{\circ} \mathrm{C}$. Next, they were rinsed for $3 \times 10 \mathrm{~min}$ in TBS, and $2 \times 5 \mathrm{~min}$ in Tris- $\mathrm{HCl}$, $\mathrm{pH}$ 7.6, and subsequently stained with filtrated diaminobenzidine tetrahydrochloride (DAB; D5905; 0.067\% in Tris- $\mathrm{HCl}$, Sigma-Aldrich; $4^{\circ} \mathrm{C}$ ), to which a $30 \%$ solution of $\mathrm{H}_{2} \mathrm{O}_{2}$ had been added immediately before use. When, upon inspection in a light microscope, the projection from POR appeared to be clearly labeled in MEC without any visible background staining, the $\mathrm{DAB}$ reaction was stopped with Tris- $\mathrm{HCl}$, and the sections were rinsed for $2 \times 5 \mathrm{~min}$ in the same buffer.

The entorhinal cortex was dissected and postfixed in the dark for $1 \mathrm{~h}$ in $2 \% \mathrm{OsO}_{4}(201030$, Merck) in $0.1 \mathrm{~m} \mathrm{PBS}, \mathrm{pH}$ 7.4. The sections were rinsed $2 \times 5 \mathrm{~min}$ in PBS and then dehydrated in ascending series of ethanol in water: 50\% (10 min), 70\% (10 min), 90\% (10 min), and in 100\% (4 $\times 15$ $\mathrm{min})$. Subsequently, the sections were put in propylenoxide (807027, Merck) for $2 \times 15 \mathrm{~min}$, followed by a mixture of propylenoxide and epoxy resin (21395, Ladd Research), first 2 volume parts propylenoxide and 1 volume part epoxy resin for $30 \mathrm{~min}$, followed by 1 part propylenoxide and 2 parts epoxy resin $(30 \mathrm{~min}$ ) before they were put in pure epoxy resin overnight. In all solutions including epoxy resin, $1.5 \%$ of the curing agent dimethylaminomethylphenol (21370, Ladd Research) was added. The sections were then embedded in epoxy resin between polyethylene foil (3M Color Laser Transparency film, CG3710) at $60^{\circ} \mathrm{C}$ overnight. All sections were inspected under a dissection microscope to determine the location of the labeled plexus in MEC. In four animals, we deemed the density of the terminal plexus sufficient for further EM analysis. These selected plexus were dissected from the sections and glued with epoxy resin on blocks of precured epoxy resin. The blocks were subsequently cured for $24-48 \mathrm{~h}$ at $60^{\circ} \mathrm{C}$.

From these blocks, series of ultrathin sections $(60-70 \mathrm{~nm})$ were cut with an ultramicrotome (Leica, EM UC6) equipped with a diamante knife (Diatome ultra $\left.45^{\circ}\right)$ and collected on formvar-coated $(0.5 \%$ in dichlorethan, Electron Microscopy Sciences) single-slot copper grids (EMS201-CU, Electron Microscopy Sciences). Sections were stained in the dark with $4 \%$ uranylacetate in $50 \%$ ethanol for 17-20 min and counterstained with $1 \%$ lead citrate (Electron Microscopy Sciences) in $0.1 \mathrm{M}$ $\mathrm{NaOH}$ for 4-5 min, and inspected with a transmission electron microscope (JEM-1011, JEOL). Digital images were taken (Olympus), and lengths of all postsynaptic densities (PSDs) and the shortest and longest diameters of each axonal bouton were measured in iTEM (5.0 Olympus Soft Imaging Solutions). Images were subsequently stored on a hard disk. Initial screening of the ultrathin sections from all blocks allowed us to select material from two animals that showed strong anterograde labeling in layers II and III of MEC and of which the ultrastructure was well preserved as to be able to obtain information about synapse morphology.

\section{Morphological and quantitative analyses of synapses}

Synapses were obtained from at least two different $50-\mu \mathrm{m}$-thick sections of each of two animals. To increase the likelihood of finding synapses, the densest part of the terminal plexus in a chosen vibratome section was isolated. The synapse type and the postsynaptic target were determined in a randomly selected reference section. All synapses in this ultrathin section were counted, and their phenotype was determined. To be included, a synapse needed to comprise a BDA labeled axon terminal, an electron-dense synaptic membrane specialization, a morphological identifiable postsynaptic element, and a distinguishable synaptic cleft. To avoid double counting, only synapses that were not visible in a parallel look-up section were used in analyses (Gundersen, 1986). Serial sections were used to certify the properties of identified synapses. In each animal, analysis was continued until a sample size $>100$ identified synapses was reached.

Synapse properties in terms of presynaptic varicosities and postsynaptic targets were determined on the basis of their overall morphology, using criteria described in detail previously (Gray, 1959; Uchizono, 1965; Colonnier, 1968). Synapses with a thick PSD, round vesicles in the presynaptic element, and a wide synaptic cleft were categorized as asymmetrical synapses, whereas synapses with a thin PSD, pleomorphic vesicles, and a narrow synaptic cleft were classified as symmetrical synapses. Postsynaptic targets were classified as spines if they had a clear cytoplasm and/or a spine apparatus. Postsynaptic targets with mitochondria and/or visible microtubules were classified as dendritic shafts.

After categorization of the synapses and postsynaptic targets, all electron micrographs were presented blindly to an unbiased independent observer who was asked to categorize the boutons and postsynaptic target according to the same criteria described above. Boutons and postsynaptic targets on which the first and second observer did not agree were discussed together and classified as undetermined if no consensus was reached or when there was consensus that not all criteria were met.

\section{Slice preparation for electrophysiology}

Slices (400 $\mu \mathrm{m}$ thickness) were prepared from Wister (Taconic) or LongEvans rats (100-150 g). All Long-Evans rats were bred in-house. We used 58 animals in total. Animals were anesthetized with isoflurane (Isofane, Vericore), subsequently decapitated, the brain quickly removed from the skull and placed in oxygenated $\left(95 \% \mathrm{O}_{2}-5 \% \mathrm{CO}_{2}\right)$ ice-cold 
ACSF as follows (mM): $124 \mathrm{NaCl}, 5 \mathrm{KCl}, 1.25 \mathrm{NaH}_{2} \mathrm{PO}_{4}, 2 \mathrm{MgSO}_{4}, 2$ $\mathrm{CaCl}_{2}, 10$ glucose, $22 \mathrm{NaHCO}_{3}$. To maintain the connectivity between $\mathrm{POR}$ and MEC, tilted sagittal slices were cut with an angle of $\sim 5$ degrees with the midsagittal plane and 85 degrees with the dorsal surface of the hemisphere (Figure 1; Vibratome 1000, Vibratome). Each slice was then transferred onto a fine-mesh membrane filter (Omni pore membrane filter, JHWP01300, Millipore) held in place by a thin Plexiglas ring (11 $\mathrm{mm}$ inner diameter; $15 \mathrm{~mm}$ outer diameter; 1-2 mm thickness), maintained in a moist interface chamber, containing the previously used ACSF, continuously supplied with a mixture of $95 \% \mathrm{O}_{2}$ and $5 \% \mathrm{CO}_{2}$ gas, and moistened by leading the gas through ACSF before it entered the chamber (Tominaga et al., 2000). The ACSF was maintained at $32^{\circ} \mathrm{C}$. For all experiments, slices rested for at least $1 \mathrm{~h}$ until used one by one in the recording chamber superfused with ACSF.

\section{Electrophysiology}

Voltage-sensitive dye (VSD) imaging. The recording chamber was positioned under a fluorescence microscope (Axio Examiner, Zeiss) and the slice stained for 3 min with the VSD RH-795 (R649, Invitrogen, 0.5\% in ACSF) (Koganezawa et al., 2008). Slices were excited with $535 \pm 25 \mathrm{~nm}$ light (bandpass), reflected by a dichroic mirror (half reflectance wave length of $580 \mathrm{~nm}$ ). Epifluorescence was detected through a longwavelength pass filter $(50 \%$ transmittance at $590 \mathrm{~nm})$ with a CMOScamera (MiCAM Ultima, BrainVision, Japan; $100 \times 100$ pixels array). When the optical recording was triggered, an electronically controlled shutter built into the light source (HL-151, Brain Vision) was opened for $500 \mathrm{~ms}$ before the start of recording to avoid both mechanical disturbance caused by the shutter system and rapid bleaching of the dye. Subsequently, the optical baseline was allowed to stabilize for $50 \mathrm{~ms}$ before stimuli were delivered. For all experiments, 512 frames at a rate of 1.0 $\mathrm{ms} /$ frame were acquired. To represent the spread of neural activity, we superimposed color-coded optical signals on the bright-field image. In this procedure, we applied a color code to the fraction of the optical signal, which exceeded the baseline noise. To reduce baseline noise, we averaged eight identical recordings acquired with a 3 s interval directly in the frame memory. Optical signals were analyzed off-line using BrainVision analyses software. Changes in membrane potential were evaluated in a ROI as fractional changes of fluorescence $(\Delta \mathrm{F} / \mathrm{F})$. Based on visual inspection of the optical signal, the region where the signal first entered MEC after POR stimulation was chosen as our ROI. The stimulation electrode was a tungsten bipolar electrode with a tip separation of 150 $\mu \mathrm{m}$. Because the POR to MEC projections originate primarily in layers II/III and V (Burwell and Amaral, 1998b), we separately stimulated layers II/III or V of the dorsal or ventral parts of POR, respectively. We used 219 slices; and in some, several stimulation positions were tested subsequently. Ultimately, we analyzed data from ventral POR layers II/III stimulation $(N=60)$, ventral POR layer V stimulation $(N=46)$, dorsal POR layers II/III stimulation $(N=56)$, and dorsal POR layer V stimulation $(N=57)$. Initially, a single pulse stimulation $(300 \mu \mathrm{s}, 0.1-0.3 \mathrm{~mA})$ was used. In case the single pulse did not cause measurable activation in MEC, four or five repetitive stimulations $(0.1-0.3 \mathrm{~mA}, 300 \mu \mathrm{s}$, at $40 \mathrm{~Hz})$ were used. At least five stimulation cycles were repeated for all experiments to assess whether or not activation was elicited. In case of MEC activation, the latency was measured from the beginning of the stimulus artifact to the onset of the response in MEC.

The recording ACSF for VSD imaging contained a low dose of the $\mathrm{GABA}_{\mathrm{A}}$ antagonist bicuculline ( $2 \mu \mathrm{M}$; bicuculline methiodide; 14343; Sigma-Aldrich), similar to the recordings made in previous studies on PER-to-LEC projections. Stimulation electrodes and parameters as well as analyses were also similar to those used in these studies (Kajiwara et al., 2003; Koganezawa et al., 2008).

To identify the area of stimulation and recording for VSD experiments, slices were postfixed in 4\% PFA for up to 1 week and subsequently kept in PBS with $30 \%$ sucrose for $>10 \mathrm{~h}$ and cut at $40-50 \mu \mathrm{m}$ thickness using a freezing microtome. Mounted sections were Nissl-stained with cresyl violet and coverslipped using Entellan. Digital images of sections were combined with the optical imaging data to identify the region in which changes in neural firing occurred.
Single-neuron recordings. Whole-cell current-clamp recording of dorsal MEC neurons was done under visual guidance using infrared differential interference contrast video microscopy as described in detail previously (Couey et al., 2013; Czajkowski et al., 2013). Patch pipettes were pulled from standard-walled borosilicate capillaries (GC120F-10, Harvard Apparatus). Whole-cell recordings were made with such pipettes filled with a solution containing the following (in $\mathrm{mM}$ ): 120 K-gluconate, 10 HEPES, 4 ATP-Mg, 0.4 GTP, $10 \mathrm{~K}$-phosphocreatine, 10 $\mathrm{KCl}, \mathrm{pH} 7.3$, adjusted with $1 \mathrm{M} \mathrm{KOH}$, and an osmolarity of $\sim 280 \mathrm{M}$, having a resistance between 4 and $7 \mathrm{~m} \Omega$. Biocytin (5\%, B4261, SigmaAldrich) was included in the solution to allow for later analysis of cell location and morphology. The seal resistance was $>1$ G $\Omega$. Recordings were made with a Multiclamp 700A Amplifier (Molecular Devices) in bridge mode. Capacitance compensation was maximal and bridge balance adjusted. The signal was low pass filtered at $3 \mathrm{kHz}$ and acquired at a sampling rate of $10 \mathrm{kHz}$ using the optical imaging system through its external input terminal. The POR was stimulated with a tungsten bipolar electrode, similar to that used for the VSD recordings, or a stimulation electrode that was covered with a glass pipette (tip diameter 1-2 $\mu \mathrm{m}$ ) filled with ACSF (compare Canto et al., 2012). Because the highest connectivity was observed from ventral POR layer II/III in VSD, we stimulated ventral POR layers II/III $(300 \mu \mathrm{s}, 0.1-1 \mathrm{~mA})$.

Immunohistochemistry. Sections, containing neurons that were filled with biocytin during the recording (see above) were fixed in 4\% PFA after the recording session. Subsequently, the slices were put in DMSO/glycerin: $2 \%$ DMSO and $20 \%$ glycerin in phosphate buffer, $\mathrm{pH}$ 7.4. Slices were resectioned into 120 - $\mu \mathrm{m}$-thick sections with a freezing microtome, subsequently washed $3 \times$ for $10 \mathrm{~min}$ in $0.125 \mathrm{M}$ PBS, pH 7.4, treated with $0.3 \% \mathrm{H}_{2} \mathrm{O}_{2}$ followed by rinsing in Tris-buffered saline (TBS-TX; $0.606 \%$ Tris, $0.875 \% \mathrm{NaCl}, 5 \%$ Triton, filled up with distilled water; $\mathrm{pH} 7.6) 3 \times$ for $10 \mathrm{~min}$. Afterward, sections were incubated in a solution of avidinbiotinylated-HRP complex (ABC, PK-6200, Vector Laboratories) in TBS-TX ( $24 \mathrm{~h}$ at room temperature following the specifications of the supplier). Peroxidase activity was visualized by incubation for $5-15 \mathrm{~min}$ in DAB-Ni in $0.125 \mathrm{M}$ PBS, $\mathrm{pH}$ 7.6, and $\mathrm{H}_{2} \mathrm{O}_{2}$. After washing in Tris- $\mathrm{HCl}$ buffer for $3 \times 10 \mathrm{~min}$, the sections were mounted on glass slides from a buffered gelatin solution $\left(0.2 \%\right.$ gelatin in Tris- $\left.\mathrm{HCl} ; 35^{\circ} \mathrm{C}\right)$ and air-dried for at least $48 \mathrm{~h}$. Sections were dehydrated and coverslipped with Entellan. Neurons were analyzed and manually reconstructed with a Zeiss microscope (Imager M), using a $40 \times(0.95 \mathrm{NA})$ objective and Neurolucida software (version 7 or 9, MicroBrightField). Recorded neurons were classified as principal neurons based on morphological properties of the soma (i.e., stellate- or pyramidal-like) and having spiny dendrites (Canto and Witter, 2012).

\section{Statistical analysis}

All numbers are reported as mean \pm SEM. We used $\chi^{2}$ tests for statistical analyses. We assessed whether there was a significant difference between the EM data obtained in the individual animals, between the VSD-data obtained in slices taken at different medial-to-lateral positions, and between the latencies recorded following different stimulation positions in POR.

\section{Results}

To optimize the use of sagittal sections for the planned EM analysis and in vitro slice experiments, in a first series of experiments $(N=6)$, we analyzed the spatial organization of the POR-toMEC projections by assessing the distribution of anterogradely labeled axons in MEC following injections of anterograde tracers in POR. Previous studies have indicated that these projections show a clear dorsoventral topographical organization (Burwell and Amaral, 1998b). Our experimental data corroborated this observation and further concurred in that the POR-to-MEC projection originated primarily in layers II/III (Fig. 1). We aimed to analyze the projections of POR to MEC, which are most comparable with the strong projections from ventral PER to dorsal LEC. Therefore, the most relevant observation was that ventral POR injections $(N=3)$ resulted in dense labeling in dorsal MEC layers 

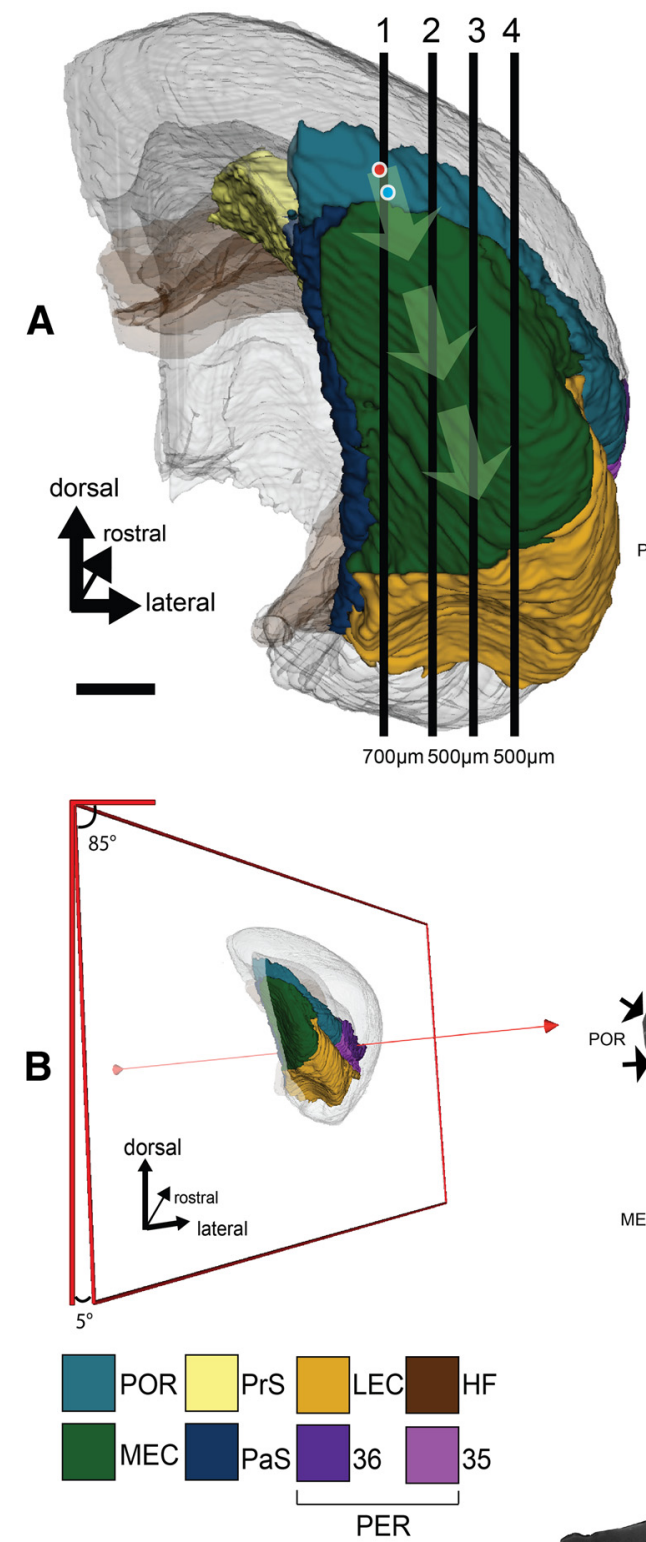
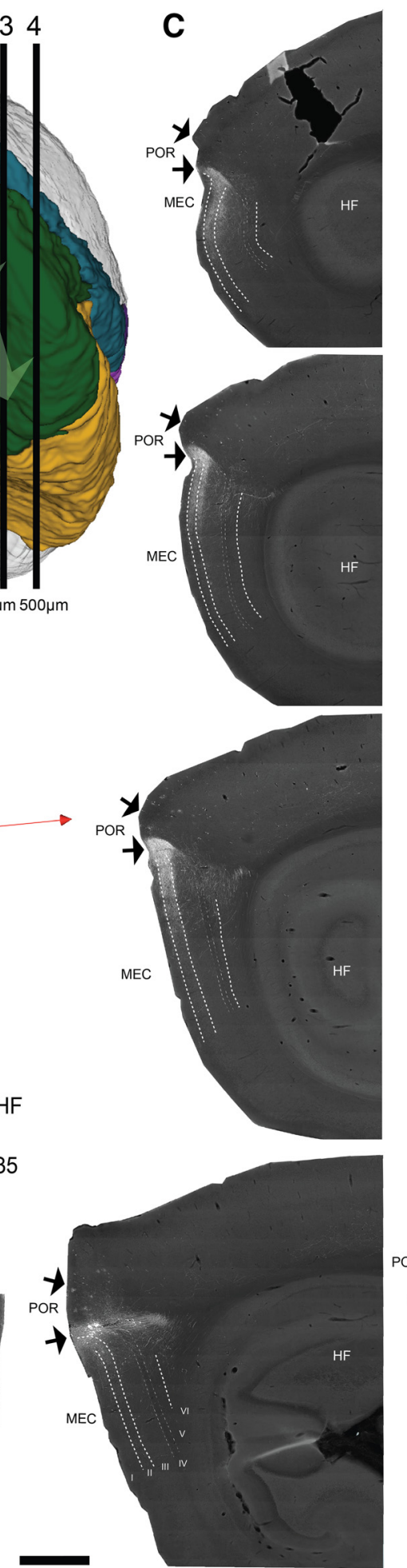

D
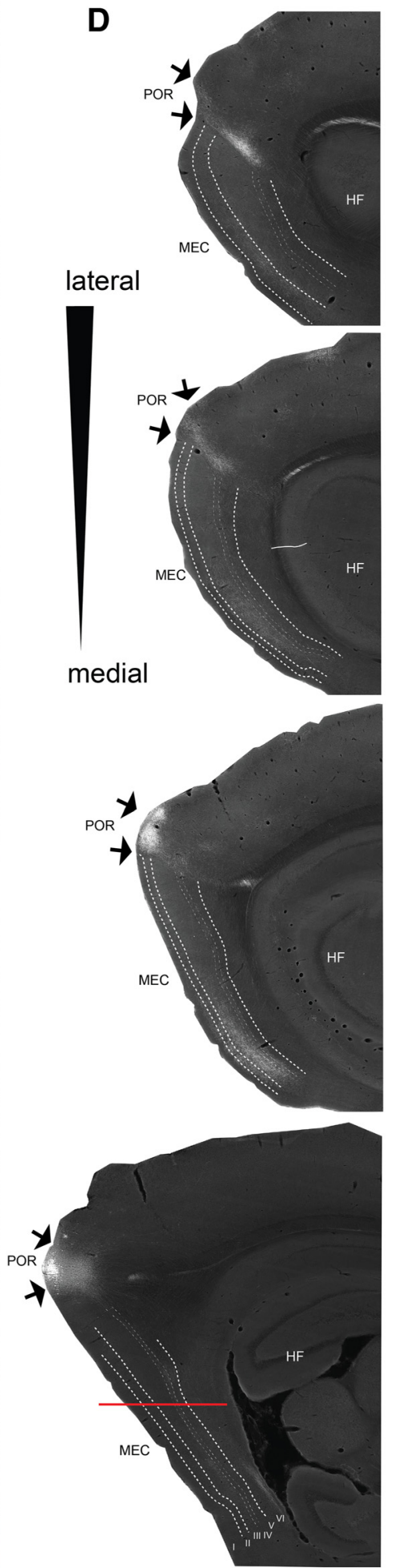

Figure 1. Spatial organization of the projections from POR to MEC. A, Posterior view of the right hemisphere of the rat brain (Boccara et al., 2015; Kjonigsen et al., 2015) showing the position of POR and MEC among the other parahippocampal domains. Vertical numbered lines (1-4) indicate the approximate position of 4 representative sagittal sections presented in $C, D$. The location of two representative injection sites of the anterograde tracer BDA into dorsal and ventral POR are represented by red and blue circles, respectively. Light green arrows emerging from the two injection sites indicate the centers of the main terminal fields in ventral and dorsal MEC, respectively. $\boldsymbol{B}$, Schematic representation of the selected orientation (5 degree tilt from the sagittal plane) of the in vitro slices based on the anatomical data (illustration prepared using the available slicing toolkit on http://software.incf.org/software/waxholm-space-atlas-of-the-sprague-dawley-rat-brain/waxholmspace-atlas-of-the-sprague-dawley-rat-brain-package/v2). C, Anterograde labeling in POR and dorsal MEC resulting from the ventral POR injection. D, Anterograde labeling in POR and ventral MEC resulting from the dorsal POR injection. There is major fiber labeling in the lamina dissecans (IV) in some of the sections. Because of the orientation of this pathway almost parallel to the plane of sectioning, this is much easier appreciated in horizontal sections taken from an animal with a comparable injection in dorsal POR, as illustrated in $\boldsymbol{E}$. Sections are arranged from medial to lateral (A1-A4). The mediolateral level of the section that contains the injection is always medial to that showing the densest anterograde labeling in MEC. $E$, Horizontal section through the entorhinal cortex, taken at a dorsoventral level indicated in D, showing the prominent axonal labeling in the lamina dissecans of MEC. HF, Hippocampal formation; LII, layer II; LIII, layer III; LV, layer V; LVI, layer VI. Scale bars: $A, C-E, 1 \mathrm{~mm}$. 

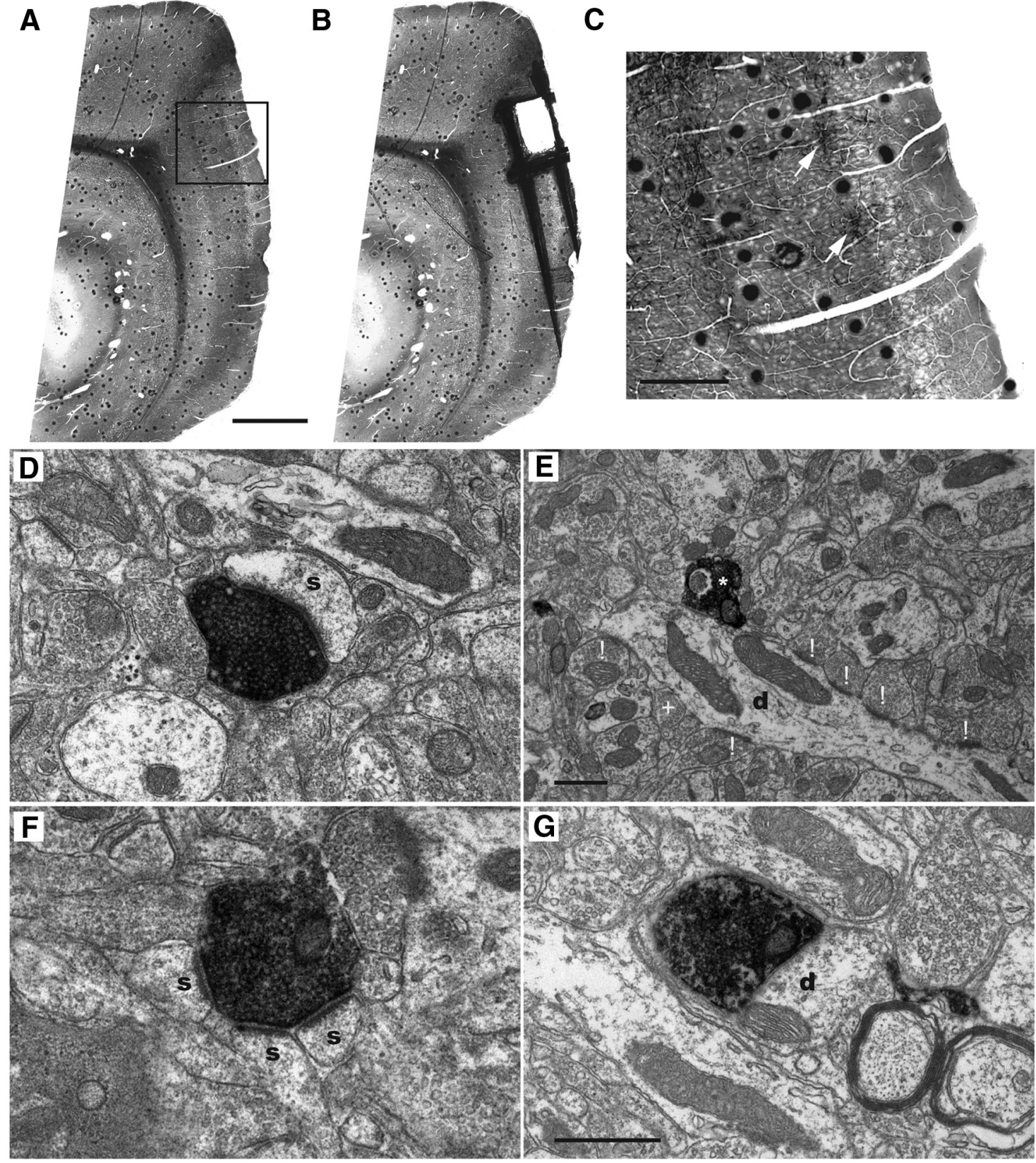

Figure 2. Electron micrographs of the main categories of anterogradely labeled synaptic terminals in dorsal MEC, layer II/III following an injection of BDA into ventral POR. $A$, Flat-embedded sagittal section through POR-MEC showing the labeled terminal plexus in layer II/III of dorsal MEC. Box represents the position of the higher-power image shown in C.Scale bar, $1 \mathrm{~mm}$. B, Same section as shown in $A$, after removal of the sample for final EM analysis. Scale bar as in $A$. $C$, High-power image of the area indicated in $\boldsymbol{A}$, showing labeled axons terminating in superficial layers of $M E C$. White arrows point to patches of labeling in layer II. Scale bar, $300 \mu \mathrm{m}$. D, A labeled axon terminal forming an asymmetrical synapse onto a spine. $\boldsymbol{E}$, A labeled axon terminal making an asymmetric synapse with a dendrite (marked with *). The dendritic segment showed additional asymmetric contacts with unlabeled terminals (marked with!) and a symmetric one (marked with + ). $\boldsymbol{F}_{\text {, }}$ A single-labeled axon terminal forming asymmetrical synapses with three spines. $\mathbf{G}$, A labeled axon terminal making a symmetric synapse with a dendrite. Scale bars: $\boldsymbol{G}($ also valid for $\boldsymbol{D}, \boldsymbol{F}), \boldsymbol{E}, 500 \mathrm{~nm}$. S, Postsynaptic spine; d, dendrite.

II and III, whereas labeling in deeper layers V and VI was sparser (Fig. 1C). In each of the tracing experiments, the sagittal section with the injection site in ventral POR was always medial to the section containing the densest labeled plexus in dorsal MEC (Fig. $1 C, D)$. In cases with a ventral POR injection, the labeled plexus is densest in the laterally adjacent tissue compartment extending for $\sim 300-700 \mu \mathrm{m}$, indicating the optimal volume of tissue to sample for EM analyses. These observations further indicated that the POR-to-MEC projections showed a preferred orientation, parallel to the dorsoventral axis of MEC, which is slightly tilted with respect to the sagittal plane of the brain (Fig. $1 A, B$ ). A comparable orientation of projections from dorsal POR to ventral MEC was observed as well $(N=3$; Figure $1 D)$. Dorsal POR further projects to ventral POR, similar to the organization of the projections from dorsal PER to ventral PER (not illustrated; Burwell and Amaral, 1998b). In most instances, we noted a preference for the labeled axons in EC to travel by way of the lamina dissecans (Fig. $1 D$; this is more easily seen in a horizontal section, shown in Fig. $1 E$, as a result of the orientation of the axons). Labeled axons could also be followed from POR to travel either through the cortical neuropil or by way of the molecular layer. Only very rarely did we observe 
Table 1. Synapse type and postsynaptic targets of labeled postrhinal terminals in layers II/III of MEC: total numbers of anterogradely labeled synapses as assessed with EM in two animals ${ }^{a}$

\begin{tabular}{|c|c|c|c|c|c|c|c|c|}
\hline \multirow[b]{2}{*}{ Target } & \multicolumn{3}{|l|}{ Asymmetrical } & \multicolumn{2}{|c|}{ Symmetrical } & \multicolumn{2}{|l|}{ Undetermined } & \multirow[b]{2}{*}{ Total } \\
\hline & Spine: normal & Spine: perforated & Dendrite & Spine & Dendrite & Undetermined & Disagreement & \\
\hline$n$ & 164 & 96 & 15 & 1 & 4 & 126 & 2 & 408 \\
\hline$\%$ & 40.196 & 23.529 & 3.676 & 0.245 & 0.980 & 30.882 & 0.490 & \\
\hline
\end{tabular}

${ }^{a}$ Synapses are group as asymmetrical, symmetrical, and undetermined synapses and their respective postsynaptic targets, spines (normal and perforated), and dendrites. Undetermined synapses are those that show either inconsistent morphological features criteria or those for which the two assessors did not agree (disagreement).

labeled axons leaving POR toward the underlying white matter to continue to deep layers of MEC. The data on preferred fiber trajectory and their tilted orientation toward the sagittal plane thus indicate that $400-\mu \mathrm{m}$-thick sagittal sections cut with a tilt of 5 degrees with respect to sagittal plane (and 85 degrees to the dorsal plane; Fig. $1 B$ ) would likely maintain the ventral POR-to-dorsal MEC projections, thus providing an optimal slice for in vitro slice experiments.

\section{Electron microscopic observations}

Using an electron microscopic approach, we subsequently assessed the type of synaptic connectivity of POR inputs terminating in layers II and III of MEC. We initially analyzed material from seven animals that received injections of BDA in the ventral portion of POR. Of these, we selected four, showing dense labeling in the dorsal portions of MEC (Fig. $2 A-C$ ), and subsequently checked the quality of the ultrastructure in ultrathin sections. We selected two animals with optimal ultrastructure and sufficient labeling in presynaptic structures, although not masking the synapse structure and vesicular morphology. In material taken from each of those two animals, random samples of labeled synaptic terminals were collected in ultrathin sections obtained from at least two or three different sagittal sections. Labeled synapses were evaluated using well-established criteria for the presynaptic and postsynaptic nature of the synaptic elements and were grouped in three types (Gray, 1959; Uchizono, 1965; Colonnier, 1968). The first type comprised asymmetrical synapses, characterized by having a thick postsynaptic density and a wide synaptic cleft. In the presynaptic terminal, spherical vesicles could be observed. The second type consisted of symmetrical synapses, which have a postsynaptic and presynaptic density of equal thickness. In addition, they have a narrow synaptic cleft and pleomorphic presynaptic vesicles. The last category comprises the "undetermined" synapses for which either a discrepancy existed between the original observation and the judgment by the second observer concerning synapse characterization, or for which not all criteria could be clearly assessed in the material at hand. Therefore, although clear synapses, these could not be classified as a symmetrical or asymmetrical synapse. For the majority of synapses analyzed, we successfully collected series of sections, providing the means to assess the morphological features of both the presynaptic and postsynaptic elements in detail. We analyzed 408 axon terminals in dorsal MEC that were labeled as the result of injections of BDA in ventral POR; and for 280 of 408 terminals, both presynaptic and postsynaptic features could be unequivocally determined by both assessors (Table 1). The majority of those determined terminals formed asymmetrical synapses $(98 \%$ or 275 of 280; Tables 1,2 ). The presynaptic elements of typical asymmetrical synapses contained a homogeneous population of circular vesicles. The postsynaptic element showed a strongly electron-dense postsynaptic membrane specialization that was at least twice as thick as the adjacent membrane portions (Fig. 2D) and faced the presynaptic docking site. As postsynaptic elements
Table 2. Synapse type and postsynaptic targets of labeled postrhinal terminals in layers II/III of MEC: observed number of identified synapse types per animal ${ }^{a}$

\begin{tabular}{|c|c|c|c|c|c|c|}
\hline \multirow[b]{2}{*}{ Target } & \multicolumn{3}{|l|}{ Asymmetrical } & \multicolumn{2}{|c|}{ Symmetrical } & \multirow[b]{2}{*}{ Total } \\
\hline & Spine: normal & Spine: perforated & Dendrite & Spine & Dendrite & \\
\hline Animal 12902 & 80 & 50 & 8 & 0 & 4 & 142 \\
\hline Animal 14402 & 84 & 46 & 7 & 1 & 0 & 138 \\
\hline Total $(n)$ & 164 & 96 & 15 & 1 & 4 & 280 \\
\hline$\%$ & 58.571 & 34.286 & 5.357 & 0.357 & 1.429 & \\
\hline
\end{tabular}

${ }^{a}$ The numbers of identified asymmetrical synapses in each of the two animals are not significantly different $\left(\chi_{(2)}^{2}=\right.$ $0.327, p=0.849$ ).

of these asymmetrical synapses, we most frequently encountered spines ( $95 \%$ or 260 of 275 ; Tables 1, 2; Fig. 2D) and less frequently dendritic shafts ( $5 \%$ or 15 of 275 ; Tables 1,2 ; Fig. $2 E$ ). Spines often showed a spine apparatus within a flocculent cytoplasm, whereas dendrites clearly show signs of microtubules (Gray, 1959). We regularly encountered complex asymmetrical synapses, where a single-labeled terminal contacted more than one spine (Fig. $2 F$ ). Our material did not allow us to reconstruct sufficient volumes to determine whether or not such spines belonged to parts of the same dendrite. Finally, the class of asymmetrical terminals onto spines comprised both continuous and perforated synapses $(58 \%$ and $34 \%$, respectively; Tables 1,2 ). We did not observe a difference between the two animals with respect to the numbers of the different asymmetrical synapse types $\left(\chi_{(2)}^{2}=0.327, p=0.849\right.$; Table 2$)$.

The remaining $2 \%$ of the total population of labeled and identified synapses was symmetrical (Tables 1,2). The latter type comprised a presynaptic terminal filled with ellipsoid or pleomorph vesicles making contact with postsynaptic elements not showing a thickened postsynaptic specialization. Between the membranes of the two synaptic elements was a clear synaptic cleft and the presynaptic element had a docking site often showing a number of aligned vesicles (Fig. $2 G$ ). The most common postsynaptic element of symmetrical synapses was a dendrite (Tables 1 , 2 ), although we observed one symmetrical synapse onto a spine. Most of the dendritic elements targeted in this study, regardless of whether it was with symmetrical or asymmetrical synapse types, most likely represent a part of smooth or very sparsely spiny dendrites. Figure $2 E$ clearly illustrates one labeled asymmetrical contact onto a longitudinally cut dendritic segment, showing an array of adjacent terminals, both symmetric and asymmetric ones, aligned in the plane of sectioning, without any spines being present.

\section{Confocal microscopy}

The electron microscopic data strongly suggest that the majority of axons that originate in ventral POR make synaptic contacts in layers II and III of MEC with spines (i.e., with dendrites of principal neurons). Likely targets are thus dendrites of layer II and III neurons, as well as the apical dendrites of layer V (Wouterlood et al., 2004; Canto et al., 2012). Stellate cells in layer II and pyramidal cells in layer III of MEC are the main origin of the projections 

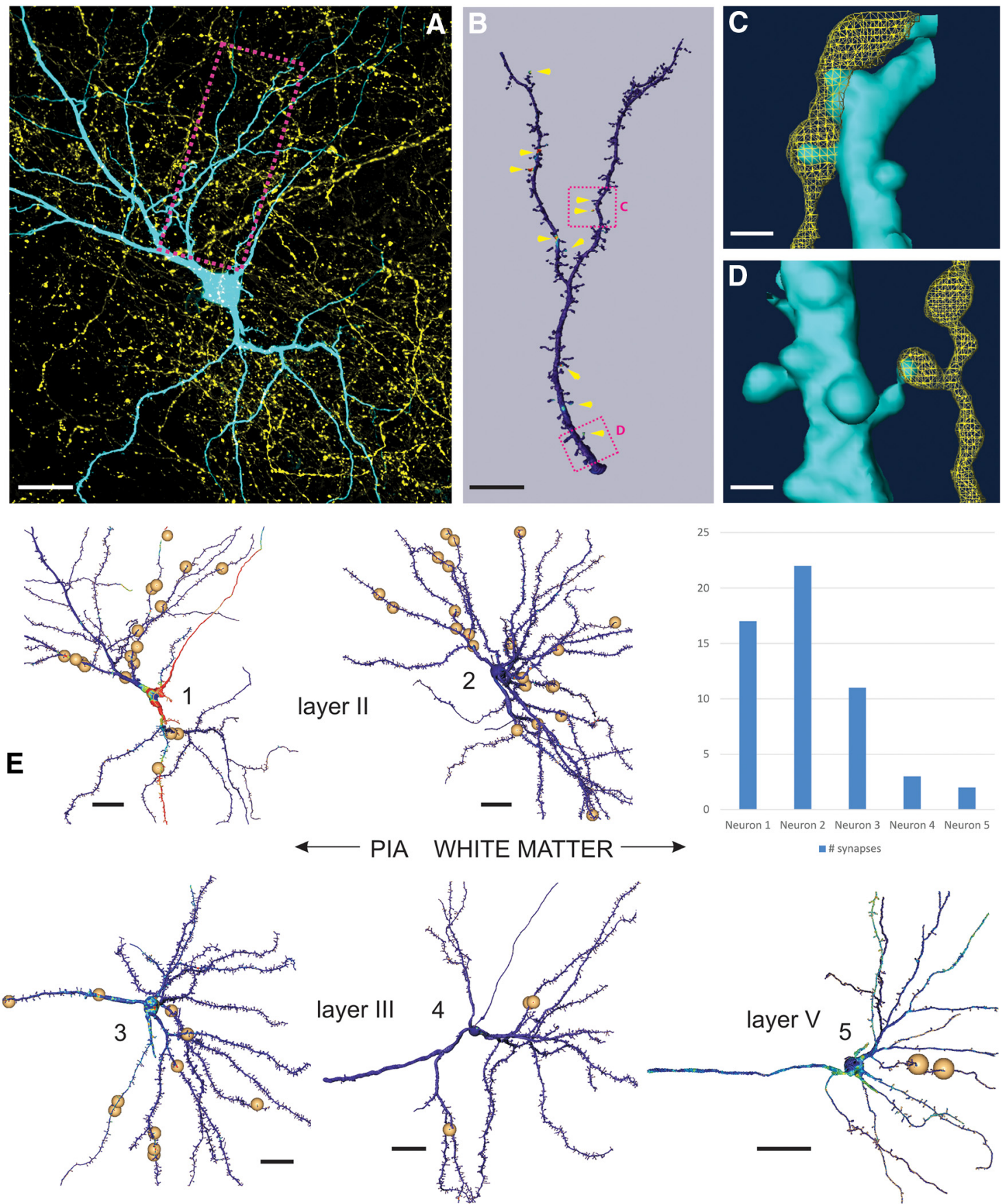

Figure 3. Identification of putative synaptic contacts onto entorhinal-hippocampal projection neurons. $A, 2 D$ projection of an intracellularly filled layer II "between oblique pyramidal and stellate cell" (cyan) (Canto and Witter, 2012) embedded in a plexus of anterogradely labeled POR axons (yellow). Red box represents the position of the dendritic portion shown in $\boldsymbol{B}$. Scale bar, $20 \mu \mathrm{m} . \boldsymbol{B}$, Surface rendering and POR input mapping of the dendritic segment indicated in $A$. The presence of BDA within $300 \mathrm{~nm}$ of the reconstructed surface is mapped and color-coded. Yellow arrowheads indicate the position of putative synaptic contacts. Two boxed areas represent the respective positions of $C, D$ (top and bottom, respectively). Scale bar, $10 \mu \mathrm{m}$. $C$, Surface reconstruction of the area shown in $\boldsymbol{B}$ (top red box), overlaid with a volume rendering of putative afferent POR fiber. Scale bar, $1 \mu \mathrm{m}$. $\boldsymbol{D}$, Surface reconstruction of the area shown in $\boldsymbol{B}$ (bottom red box), overlaid with a volume rendering of putative afferent POR fiber. Scale bar, $1 \mu \mathrm{m}$. $E$, 3D reconstructions of five representative neurons in MEC, with the positions of putative synaptic contacts, as marked by the position of the small spheres. Neuron 1 is the layer II cell shown in A. Neuron 2 is a layer II stellate cell. Neurons 3 and 4 are layer III pyramidal cells. Neuron 5 represents a layer V pyramidal cell. Scale bars (all neurons), $20 \mu \mathrm{m}$. Inset top right, Number of putative synapses for neurons $1-5$.

to the hippocampus, although neurons in layer $\mathrm{V}$ contribute to these projections as well (Cappaert et al., 2014). Therefore, in a next series of experiments $(N=6)$, we used a confocal approach to assess whether neurons that project to the hippocampal formation might be among the targeted neurons. We intracellularly filled retrogradely labeled hippocampal projection cells in layers II and III of MEC that are located inside the labeled POR axonal terminal plexus. We also filled retrogradely labeled layer $\mathrm{V}$ cells that were positioned directly deep to the labeled plexus. In total, we analyzed 27 neurons identified as hippocampal-projecting, in 12 sagittal slices. Of this sample, 19 neurons received putative synaptic inputs from POR (layer II, $N=8$; layer III, $N=8$; layer $\mathrm{V}, N=3$; Fig. 3). Unfortunately, the intracellular fillings of the three layer $\mathrm{V}$ cells were incomplete in that they did not include 

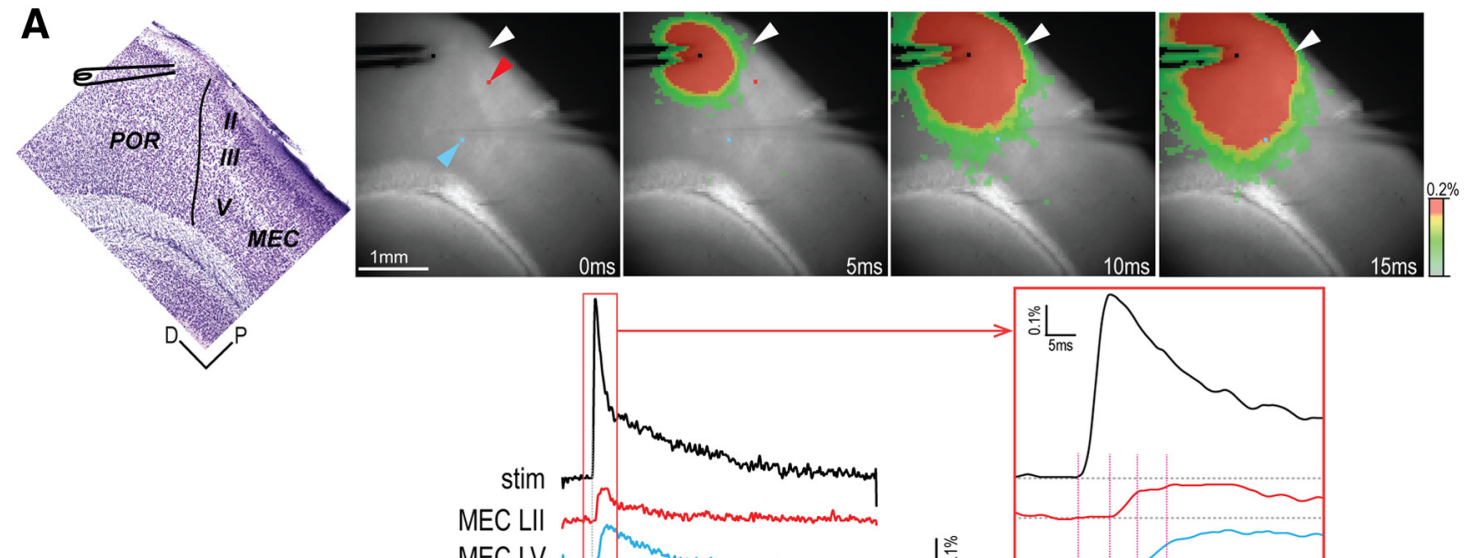

B
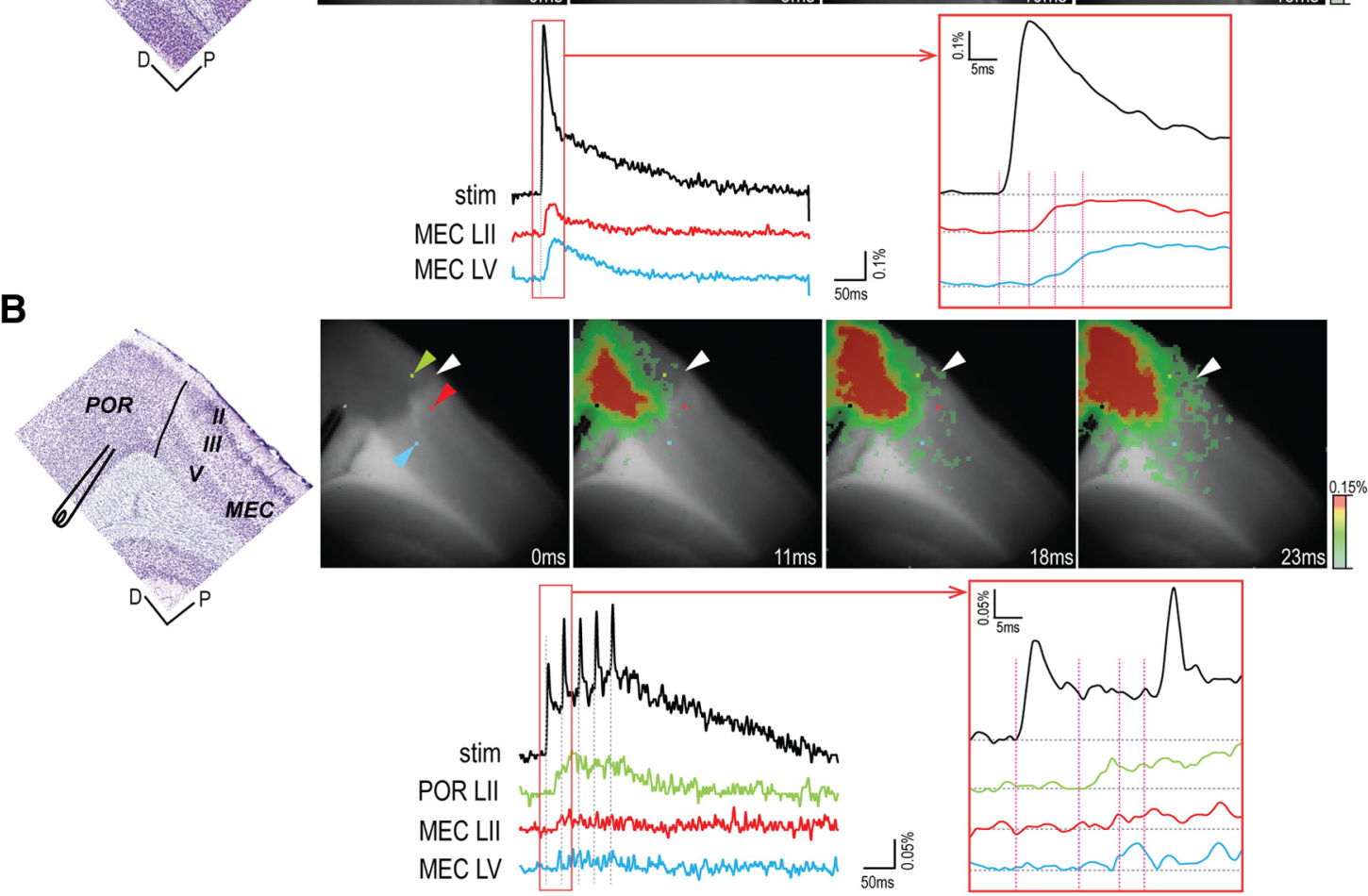

Figure 4. Propagation pattern to MEC of activity evoked in POR. A, Direct propagation from ventral POR layer II to dorsal MEC. $\boldsymbol{B}$, Propagation via POR layer II from dorsal POR layer V. Top, Left to right, Position of the stimulating electrode in a Nissl-stained thin section cut from the fixed slice after the recording experiment, and series of four selected images (time indicated below each image). Bottom, Optical signal traces from the stimulation site and the recording sites. The signal at the site of stimulation is indicated in black. Each recording site is indicated with a colored pixel (corresponding colored arrowheads; top), and the obtained signals are color-coded correspondingly. Right, Boxed area from the left panel with a higher time resolution. Vertical lines indicate the time of the images shown in the top. White arrowhead indicates the border between POR and MEC. D, Dorsal; P, posterior.

the complete apical dendrite because this was not maintained in the slice. This implies that we observed putative synapses onto the basal dendrites of these layer $\mathrm{V}$ neurons, likely representing inputs from the sparser axonal plexus in layer $\mathrm{V}$ (Fig. 1C,D) (Burwell and Amaral, 1998b). We observed a substantial variability in the number of putative synapses, ranging from 2 to 22 (Fig. 3E). This variability likely correlates with differences in the density of the anterogradely labeled plexus of POR inputs (Czajkowski et al., 2013). In view of the low number of synaptic contacts on a substantial number $(N=16)$ of the analyzed neuronal population, we did not quantitatively analyze the distribution of putative synapses along the dendritic tree. However, the neurons with a high number of putative synapses, all layer II neurons $(N=3$; Fig. $3 E$ ) did not show a preferred distribution of these putative contacts over any specific parts of the dendritic tree.

\section{Electrophysiology VSD imaging}

Together, the EM and confocal data thus showed that the majority of POR-to-MEC axons make putative excitatory projections, preferentially targeting principal neurons in MEC. We therefore predicted that stimulation in POR would result in an overall excitatory effect in MEC (i.e., transfer of POR-induced activity to MEC). Such findings would thus be markedly different from the lack of evoked activity in LEC following stimulation of PER (Ka- jiwara et al., 2003; Pelletier et al., 2004; de Curtis and Paré, 2004; Paz et al., 2006; Koganezawa et al., 2008). Based on our anatomical observations, we used tilted sagittal slices for the in vitro electrophysiology (see above; Fig. 1), to maintain a substantial component of the projections from ventral POR to dorsal MEC in a 400- $\mu \mathrm{m}$-thick slice. To mimic the recording situations in our previous studies on PER-to-LEC connections, we applied the same concentration of the $\mathrm{GABA}_{\mathrm{A}}$ antagonist bicuculline $(2 \mu \mathrm{M})$ to the bath solution (Kajiwara et al., 2003; Koganezawa et al., 2008).

In 64 tilted slices, taken from 25 animals, stimulation in layer II/III or $\mathrm{V}$ of either the dorsal or ventral part of the postrhinal cortex evoked activity in MEC (Fig. 4). For each animal, we recorded from all sagittal slices that contained POR and MEC. In view of recent reports that neurons in MEC show gradually changing properties along the medial-to-lateral axis (Canto and Witter, 2012), data from all slices were analyzed according to the medial-to-lateral position. In $26 \%$ of the recording sessions ( $N=$ 58 of a total of 219 recordings), evoked responses were limited to POR without eliciting responses in MEC. In the majority of these cases, the stimulation site was in deep layers of dorsal POR, which, according to anatomical data (Burwell and Amaral, 1998b), do not or only weakly project to MEC. These slices were not further considered. In the remaining slices, we did observe 
activation of MEC, although striking differences in latencies were apparent. In line with anatomical observations (Burwell and Amaral, 1998b; present study), we observed in $31 \%$ of the recordings $(N=19$ of 60$)$ that stimulation in superficial layers of ventral POR resulted in activation in MEC with latencies $\sim 4 \mathrm{~ms}$ (3.9 \pm $1.1 \mathrm{~ms}$; Figs. $4 A, 5 A$ ). Such short latencies are taken to indicate that the evoked excitation in MEC represents the effects of monosynaptic innervation (Tolner et al., 2007). These results were strikingly different from those recorded under similar conditions for PER-to-LEC projections (Kajiwara et al., 2003; Koganezawa et al., 2008). According to the latter studies, stimulation in PER did not elicit activation in LEC even with repetitive stimulation or using higher concentrations of bicuculline (up to $5 \mu \mathrm{M}$ ) (Kajiwara et al., 2003).

Short latency activations of MEC ( $<5 \mathrm{~ms})$ were significantly less common when the stimulation electrode was in portions of POR other than ventral POR superficial layers: ventral POR layer V, $15 \%(N=7$ of 46$)$; dorsal POR layer II, $9 \%(N=5$ of 56$)$; and dorsal POR layer V, $2 \%(N=1$ of 57$)$ (Figure $5 B-D)$; ventral POR superficial stimulation versus the three other simulation sites $\left(\chi_{(1)}^{2}=19.2, p<0.001\right)$. In the majority of recordings with stimulations in the latter three domains $(43 \%)$, we observed responses in MEC with latencies $>5 \mathrm{~ms}$ (Fig. $4 B$; for the details of latencies, see Fig. $5 B-D$ ). In such slices, we used the spatiotemporal information in the VSD signal to analyze the propagation patterns and latencies of evoked activities in ventral POR layer II and MEC. These analyses revealed that evoked activities in layer II of ventral POR always preceded activity in MEC. In such cases, the responses in MEC appeared $\sim 5 \mathrm{~ms}$ after the onset of activation in ventral POR layer II (Fig. 4B). This pattern thus corroborated the existence of a monosynaptic input from ventral POR layer II to MEC and suggested that an intrinsic POR network is capable of driving neurons in layer II of ventral POR, which project to dorsal MEC.

When activation occurred in MEC, regardless of stimulation site or latency, it generally occurred in layers II, III, and V, having corresponding latencies (Fig. $4 A, B)$. In $10 \%$ of the cases $(N=22$ of 219), we observed evoked neural activity only in either the superficial or the deep layer of MEC. Because this may indicate a partial loss of connectivity due to slicing angle, we classified this propagation pattern separately in our analysis (Fig. 5, "superficial/deep"). Grouping all recordings according to the lateral to medial position of the slices in which they were obtained (Fig. 5) showed that the lateral- and medial-most slices had less monosynaptic connectivity ( $8 \%$ of recordings in such slices, $N=3$ of 38) compared with slices taken centrally through the POR-MEC complex (17\% of all centrally located recordings, $N=30$ of 181). This difference was, however, not significant $\left(\chi_{(1)}^{2}=1.84, p=\right.$ 0.173 ). We also reanalyzed all responses in MEC having latencies $>5 \mathrm{~ms}$, except those resulting from stimulation of ventral POR layer II. We estimated the latencies following activation of ventral POR layer II in relation to the lateral to medial position of the slices. This analysis indicated that, in slices taken from the center of the POR-MEC complex, the monosynaptic connectivity from ventral POR layer II to MEC seemed preserved best $(67 \%$ monosynaptic connections in central slices, $N=51$ of 76 vs $42 \%$ in medially or laterally positioned slices, $N=5$ of 12). However, similar to the previous analysis, this apparent difference was not significant $\left(\chi_{(1)}^{2}=2.89, p=0.0857\right)$. The lack of significance may be due to lack of statistical power, and we therefore still suggest that our results may reflect a slight variation in the orientation of POR-MEC projections, such that the selected 5 degree tilt to the sagittal plane of our slices is optimal for the central part of POR-MEC and suboptimal for more medial or lateral levels.

\section{Single-cell recordings}

The data obtained with VSD imaging provided strong indications that activation in ventral POR results in activation in dorsal MEC with a very high probability, which is in striking contrast to reports that activation of LEC following stimulation of PER only occurs with a very low probability (de Curtis and Paré, 2004). To corroborate our anatomical findings pointing to principal cells in layers II, III, and V as the main recipients of excitatory inputs from POR, we performed whole-cell recordings in 77 principal neurons in all layers of MEC (47 slices from 33 animals). In a previous study, we electrophysiologically studied projections from the presubiculum and parasubiculum to MEC (Canto et al., 2012). These inputs terminate strongly in layers I-III, comparable with POR projections. In the latter study, we observed that neurons in all layers, including neurons in layer VI, received monosynaptic inputs. Therefore, we included some recordings of layer VI neurons in the present study.

Based on our VSD data, we opted to do all our recordings in tilted sagittal slices taken at the center of the POR/MEC complex while stimulating in layer II of ventral POR. In contrast to the VSD imaging, in the single-cell recordings, we did not use bicuculline to suppress $\mathrm{GABA}_{\mathrm{A}}$-mediated transmission. All recorded cells were non-fast-spiking, indicative for principal neurons, which we corroborated by subsequent morphological assessment (for criteria, see Materials and Methods) (Canto and Witter, 2012).

The VSD signal reflects membrane depolarizations, so as such does not differentiate excitatory effects on principal cells from interneurons. In some slices $(N=6)$, we therefore obtained both VSD imaging data and whole-cell recordings (Fig. 6A). When comparing the whole-cell signal with the optical signal of the pixel (pixel diameter $=25 \mu \mathrm{m}$ ) that colocalizes with the position of the recorded neuron, the two signals showed a close correspondence with respect to onset and shape of the response, regardless of whether we recorded a short latency (layer II neuron; Fig. 6A, left) or a long latency response (layer VI neuron; Fig. $6 \mathrm{~A}$, right). This supports the conclusion that the population data as obtained with VSD data actually indicated that POR inputs are excitatory, mainly targeting principal neurons in MEC.

We next analyzed the full single-cell dataset by grouping recorded neurons according to their mediolateral positions in MEC as well as per layer and grouped the neurons according to the latency between stimulus and response onset (Fig. 6B, C). Stimulation in ventral POR layer II reliably evoked EPSPs in a substantial number of neurons in layer II (31\%), layer III (33\%), and layer $\mathrm{V}(40 \%)$, with latencies between 3 and $6 \mathrm{~ms}(N=24 ; 4.96 \pm$ $0.79 \mathrm{~ms}$ ). In layer VI, all response latencies were $>6 \mathrm{~ms}$ (Fig. 6). We did not observe any inhibitory postsynaptic responses (IPSPs), which differed markedly from reported data on the PERto-LEC projection, where PER stimulation evoked IPSPs in $25 \%$ of LEC neurons (in the remainder 75\%, both IPSPs and EPSPs were observed; in $33 \%$ of the latter population, IPSP onset preceded EPSP onset) (Apergis-Schoute et al., 2007). In a few instances $(N=6)$, we observed response latencies $<3 \mathrm{~ms}$, likely representing direct stimulation due to volume conduction. EPSPs with longer latencies ( $>6 \mathrm{~ms} ; N=22$ ) were also present, likely representing multisynaptic activation. 
A

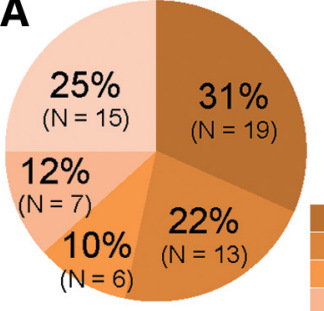

vPOR superficial
$L<5$

$5<L<10$
$L>10$

superficial/deep

POR only lateral <
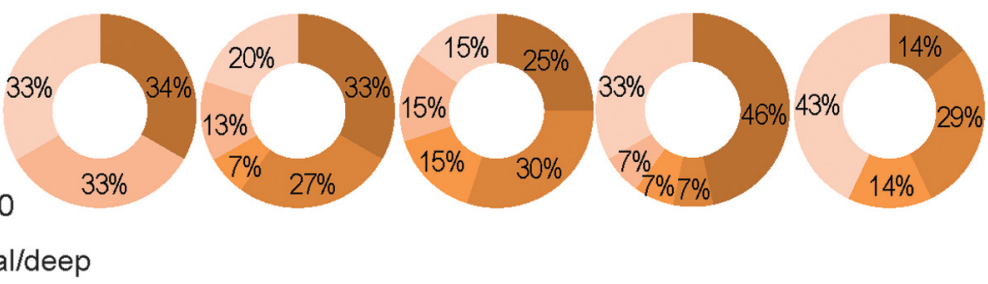

$4 \%$

B

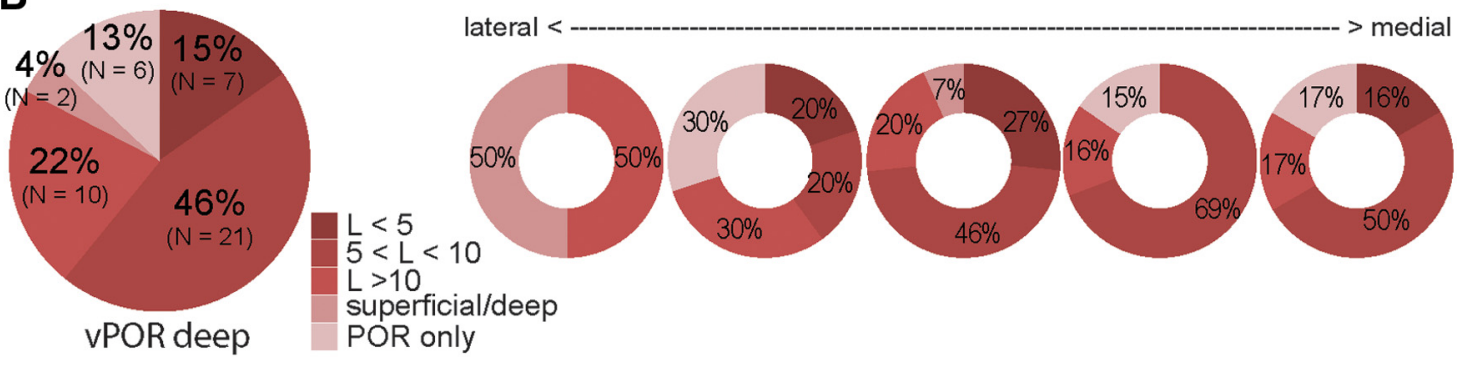

C

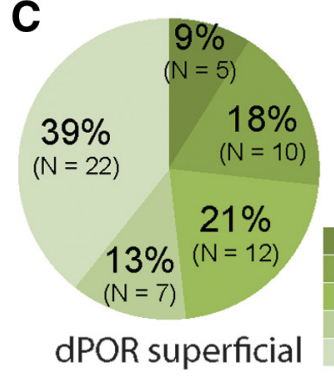

lateral $<$ medial

$L<5$

$5<L<10$
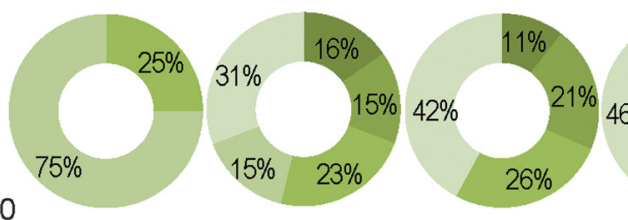

superficial/deep

POR only
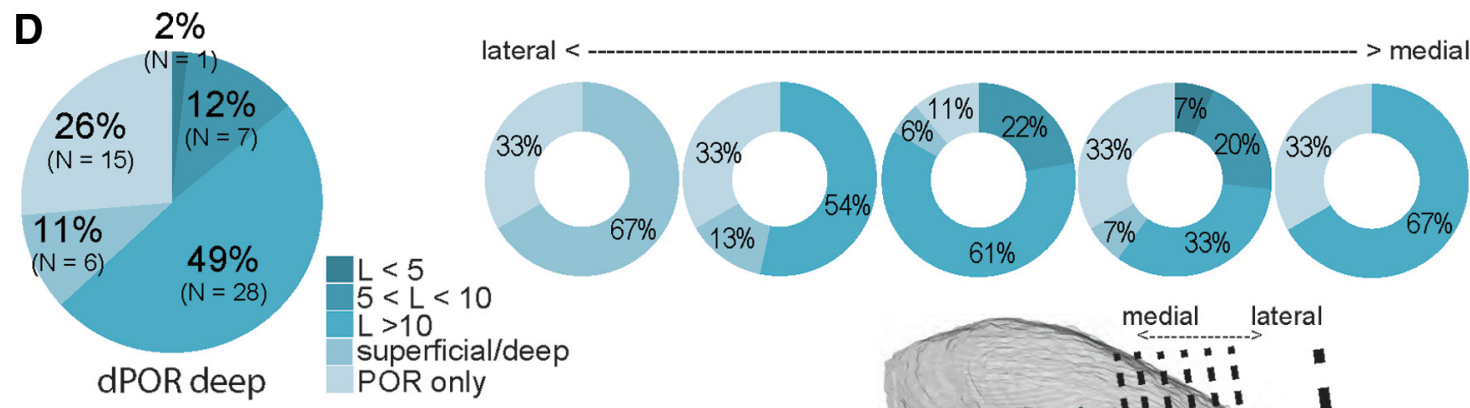

$L>10$

POR only
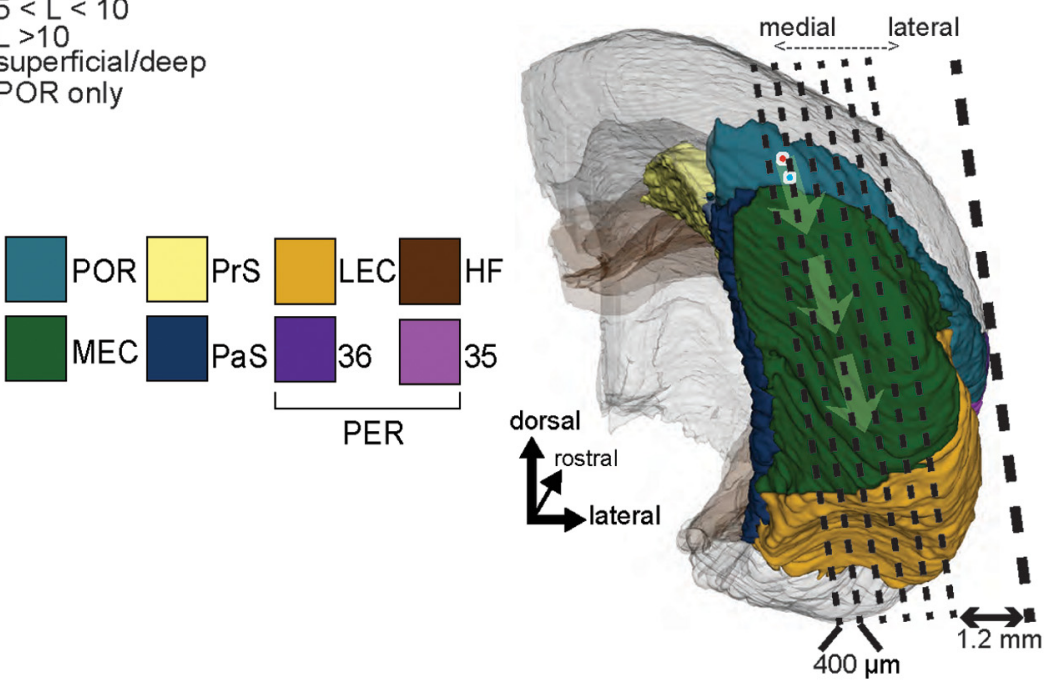

Figure 5. Grouping of the slices according to response latencies, measured with VSD. $A$, Ventral POR superficial stimulation $(N=60)$. B, Ventral POR deep stimulation ( $N=46)$. C, Dorsal POR superficial stimulation $(N=56)$. D , Dorsal POR deep stimulation $(N=57)$. Left, Pie charts represent the percentage of slices, averaged across all mediolateral positions, showing response latencies in MEC as indicated by the color code. Ventral POR superficial stimulation $(A)$ resulted in short latency responses in a higher number of slices compared with the other stimulation sites $\left(\chi_{(1)}^{2}=19.2\right.$ $p<0.001)(B-D)$. $\boldsymbol{A}-\boldsymbol{D}$, Right, Doughnut charts represent the percentage of slices, grouped with respect to their relative mediolateral position, showing (Figure legend continues.) 


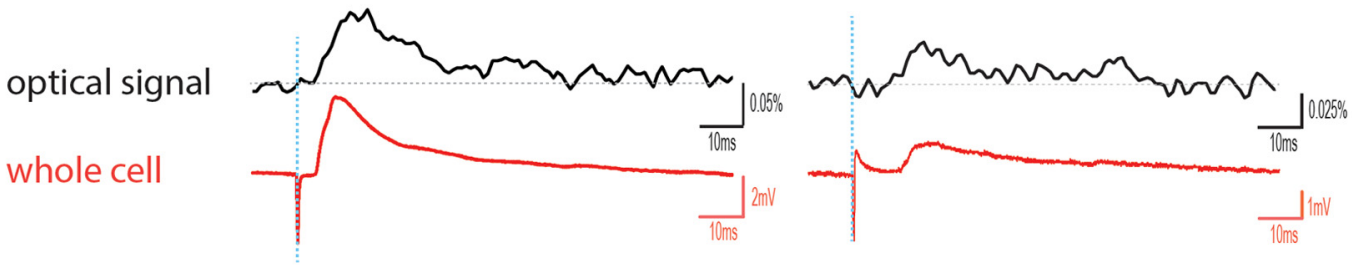

B
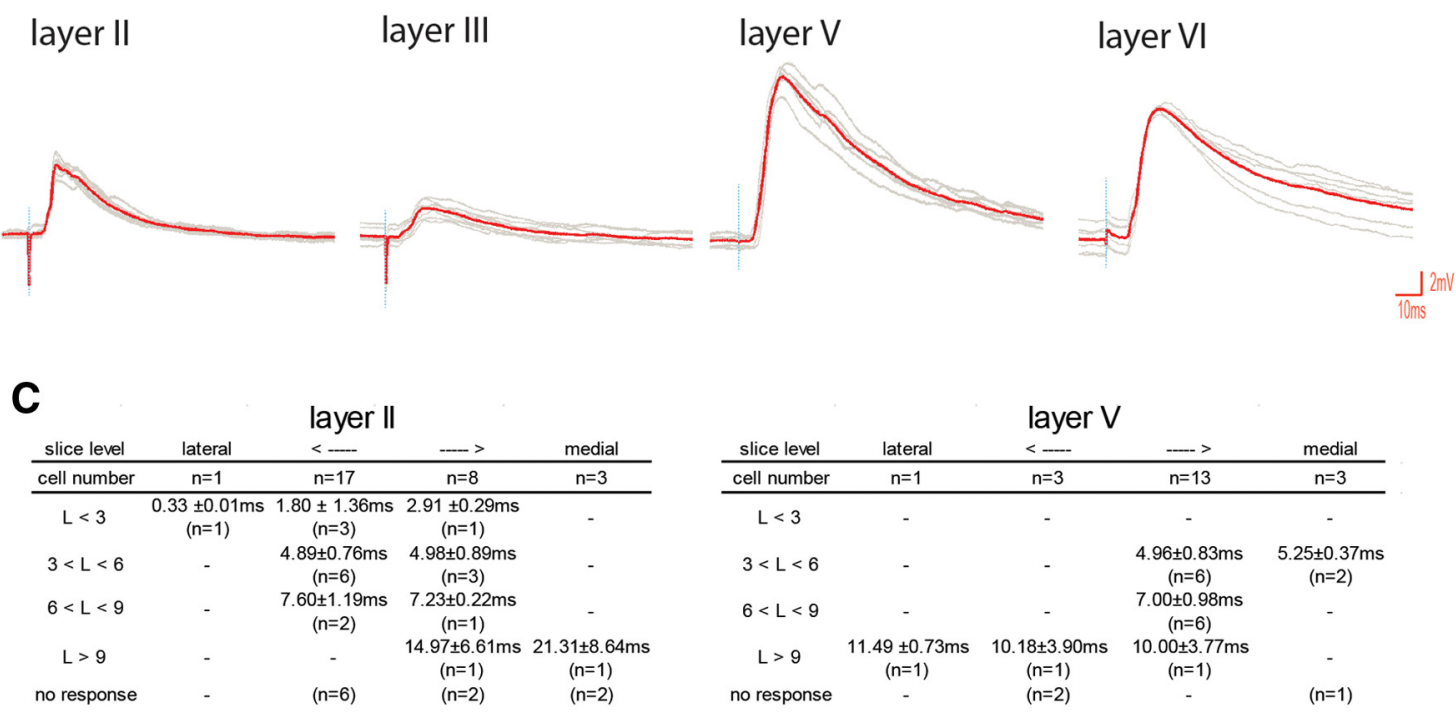

layer III

\begin{tabular}{|c|c|c|c|c|c|}
\hline slice level & lateral & $<\ldots$ & 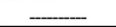 & $\ldots$ & medial \\
\hline cell number & $n=1$ & $n=3$ & $n=4$ & $n=9$ & $n=4$ \\
\hline$L<3$ & - & - & - & $\begin{array}{c}2.83 \pm 0.13 \mathrm{~ms} \\
(\mathrm{n}=1)\end{array}$ & - \\
\hline $3<L<6$ & $\begin{array}{c}5.37 \pm 0.23 \mathrm{~ms} \\
(n=1)\end{array}$ & $\begin{array}{c}3.65 \pm 0.56 \mathrm{~ms} \\
(n=1)\end{array}$ & $\begin{array}{c}5.25 \pm 0.70 \mathrm{~ms} \\
(\mathrm{n}=2)\end{array}$ & $\begin{array}{c}5.17 \pm 1.26 \mathrm{~ms} \\
(n=2)\end{array}$ & $\begin{array}{c}3.70 \pm 0.15 \mathrm{~ms} \\
(n=1)\end{array}$ \\
\hline $6<L<9$ & - & - & - & - & $\begin{array}{c}6.52 \pm 0.59 \mathrm{~ms} \\
(\mathrm{n}=2)\end{array}$ \\
\hline$L>9$ & - & $\begin{array}{c}18.64 \pm 0.68 \mathrm{~ms} \\
(n=1)\end{array}$ & - & $\begin{array}{c}38.99 \pm 13.20 \mathrm{~ms} \\
(n=1)\end{array}$ & - \\
\hline no response & - & $(n=1)$ & $(n=2)$ & $(n=5)$ & $(n=1)$ \\
\hline
\end{tabular}

\begin{tabular}{cccc} 
slice level & lateral & $<->$ & medial \\
\hline cell number & $\mathrm{n}=1$ & $\mathrm{n}=4$ & $\mathrm{n}=2$ \\
\hline $\mathrm{L}<3$ & - & - & - \\
$3<\mathrm{L}<6$ & - & - & - \\
& - & - & - \\
$6<\mathrm{L}<9$ & $\begin{array}{c}7.33 \pm 1.26 \mathrm{~ms} \\
(\mathrm{n}=1)\end{array}$ & $\begin{array}{c}7.64 \pm 0.61 \mathrm{~ms} \\
(\mathrm{n}=3)\end{array}$ & $\begin{array}{c}6.79 \pm 1.40 \mathrm{~ms} \\
(\mathrm{n}=1)\end{array}$ \\
$\mathrm{L}>9$ & - & $\begin{array}{c}9.63 \pm 0.80 \mathrm{~ms} \\
(\mathrm{n}=1)\end{array}$ & - \\
no response & - & - & $(n=1)$
\end{tabular}

Figure 6. Ventral POR layer II stimulation evoked EPSPs in individual MEC neurons. $\boldsymbol{A}$, Simultaneous recordings of an optical signal (top, black trace) and a whole-cell signal (bottom, red trace). Left, Recording in a layer II neuron. Right, Recording in a layer VI neuron. Vertical lines in the traces indicate the moment of stimulation. $\boldsymbol{B}$, Representative recordings in layers II, III, V, and VI of MEC. The average postsynaptic response (red) is superimposed over the 6 individual recordings (gray). $\boldsymbol{C}$, Details of the latencies between stimulation and onset of the EPSPs. For each layer, we show the relative lateral to medial position of the sagittal slices, the total number of cells recorded in each slice level across all animals, the observed latencies ( $\mathrm{L})$ clustered in 4 time bins ( $\mathrm{L}<3 \mathrm{~ms} ; 3<\mathrm{L}<6 ; 6<\mathrm{L}<9$; $\mathrm{L}>9$ ), and the number of neurons in each latency bin.

\section{Discussion}

In this paper, we report the results of a combined anatomical and electrophysiological approach to study the transmission characteristics of POR-to-MEC projections. Our ultrastructural data clearly indicate that that the majority of synapses form excitatory contacts onto principal cells. The overall excitatory nature of the POR-MEC projection is confirmed by our in vitro VSD imaging approach and single-cell recordings. The single-cell recording data further support the conclusion that principal cells are among

(Figure legend continued.) color-coded latencies. Response latencies depend on the position of the stimulation as well as the relative mediolateral position of the slice (the approximate mediolateral position of the five $400-\mu \mathrm{m}$-thick slices is indicated in the inset; compare with Fig. 1A). the postsynaptic targets by showing that principal cells in layers II, III, and V receive monosynaptic inputs from POR. The confocal data further indicate that, in these layers, principal cells that project to the hippocampal formation are among the target cells. The observation that layer $\mathrm{V}$ principal cells are innervated by POR projections, preferentially, though not exclusively, terminating in layers II and III, is similar to what has been reported for other inputs distributing preferentially to superficial layers. For example, inputs from presubiculum and parasubiculum, targeting layers I/III or II of MEC, respectively, synapse onto layer V pyramidal cells (Canto et al., 2012). These observations indicate that layer $\mathrm{V}$ cells form a relevant component of the integrative neural network in MEC (Canto et al., 2012; Witter et al., 2014). In contrast to the findings for the presubicular and parasubicular inputs (Canto et al., 2012), we did not find evidence for mono- 
synaptic inputs to neurons in layer VI. Because the dendrites of layer VI principal neurons are largely confined to layer VI (Canto and Witter, 2012), this lack of monosynaptic innervation corroborates the observation that most of the POR-to-MEC projections travel by way of the cortical neuropil, not using the underlying white matter and therefore not traveling through layer VI, which differs from projections originating in the presubiculum and parasubiculum (Canto et al., 2012).

To analyze the spatial and functional distribution of PORMEC connectivity, we used VSD imaging. Because our tracing study corroborated a previous report (Burwell and Amaral, 1998b), showing that dorsal POR projects ventrally in MEC, while ventral POR projects dorsally in MEC, we stimulated dorsal POR or ventral POR to see the neural activity propagation. We reliably observed monosynaptic inputs from ventral POR to dorsal MEC, but we have not been able to characterize the inputs from dorsal POR to ventral MEC (see below). Instead, we observed that, when activity propagated to MEC, the evoked activities propagated via ventral POR layers II/III into dorsal MEC, corroborating that neurons in layers II/III of POR are the main origin of projections to MEC. The data further indicate that an intrinsic POR network is capable of driving neurons in layer II of POR, which project to MEC. This differs from what has been reported in case of intrinsic PER connectivity, where the net result of dorsal PER stimulation is inhibition in ventral PER (de Curtis and Paré, 2004).

The lack of monosynaptic activation from dorsal POR to ventral MEC is likely due to the rather long distance between origin and termination areas, making it likely that these axons were cut in our slice preparations. Our results further show that the PORinduced local activation in dorsal MEC does not result in subsequent activation at more ventral levels of MEC. This may reflect a variety of known features of the local MEC network, including strong inhibition between layer II stellate cells, although this is not the case for neurons in layer III or layer V (Jones, 1994; Dhillon and Jones, 2000; Couey et al., 2013; Pastoll et al., 2013). Alternatively, the preferred orientation, parallel to the rhinal fissure, of long intrinsic entorhinal connections (Witter et al., 1989; Dolorfo and Amaral, 1998), indicates that sagittal slices with only a slight tilt as used in the present study will likely not optimally preserve long-range intrinsic connections in MEC.

All data consistently indicate that the POR-to-MEC projection differs from the PER-to-LEC pathway. Our ultrastructural data are strikingly different from what has been reported for the PER-to-LEC pathway, which comprises a majority of anatomically defined excitatory projections terminating on inhibitory interneurons (Pinto et al., 2006) together with direct inhibitory projections onto principal neurons (Apergis-Schoute et al., 2007). In line with the latter ultrastructural findings, VSD imaging of the PER-to-LEC pathway points to a very low probability for stimulation of PER, either in dorsal or ventral parts, to result in activation of LEC, except when inhibition is diminished through local application of GABA-a receptor antagonists (Kajiwara et al., 2003; Biella et al., 2010), or coinciding activation of two excitatory pathways (Kajiwara et al., 2003; Pelletier et al., 2004; Paz et al., 2006; but see Biella et al., 2010). Our VSD data in case of POR-to-MEC show the opposite (i.e., a very high probability that stimulation in ventral POR results in evoked activity in the adjacent dorsal MEC). This is in accordance with the EM and single-cell recording data, indicating a main excitatory projection onto principal neurons. Although we did not include direct comparisons between the two pathways in our VSD analyses, it is important to emphasize that the recording conditions used in the current study were similar to those used in two studies on the PER-to-LEC projections (Kajiwara et al., 2003; Koganezawa et al., 2008).

The conclusion that the strong inhibitory gating mechanism that controls PER-to-LEC transmission does not exist in case of transmission from POR to MEC is in contrast with a report in the isolated guinea pig brain preparation. Using this preparation, it was shown that stimulation in POR, similar to stimulation in PER, does not result in activation in either MEC or LEC, respectively (Biella et al., 2010). The latter authors also report that coincident activation of either two cortical inputs along the rostrocaudal axis of PER or POR or of cortex and the lateral nucleus of the amygdala did not lead to excitatory responses in EC in the guinea pig, also in contrast to what was found in the rat (Kajiwara et al., 2003; Pelletier et al., 2004). This difference was explained by the fact that the rat data were based on in vitro slice studies where bicuculline, a GABA-a receptor antagonist, was used (Biella et al., 2010). In the present study in the rat, in line with our previous VSD analyses of the PER-to-LEC projection (Kajiwara et al., 2003; Koganezawa et al., 2008), we used only a low dose $(2 \mu \mathrm{M})$ of bicuculline in the bath medium of the slices. Moreover, we did not apply bicuculline for the single-cell recordings and still observed monosynaptic excitatory inputs, in line with the EM observations. Therefore, it is more likely that the guinea pig and rat brains are different in this respect. It would be of interest to have access to ultrastructural data in the guinea pig to resolve this.

\section{Functional relevance}

In the rat, the stable firing of networks of individual grid cells in MEC forms a continuous representation of the environment (Hafting et al., 2005; Moser et al., 2014). We propose that the POR-to-MEC pathway provides a continuous, nongated transfer of contextual information to MEC (Bucci et al., 2000, 2002; Norman and Eacott, 2005). Other excitatory inputs to MEC, like those originating in the presubiculum and the parasubiculum, the retrosplenial cortex, and also the hippocampal fields CA2, CA1, and subiculum (McNaughton et al., 2006; Canto et al., 2012; Bonnevie et al., 2013; Couey et al., 2013; Czajkowski et al., 2013; Rowland et al., 2013; Moser et al., 2014), may provide additional continuous inputs that are relevant for the wide variety of spatially modulated neurons, present in MEC (Moser et al., 2014). In contrast, LEC neurons fire more discretely, strongly related to external sensory events that are part of an experience (Deshmukh and Knierim, 2011; Neunuebel et al., 2013). This notion is consistent with the idea that the PER-to-LEC pathway would be instrumental to signal changes in those sensory inputs and thus that the entry of perirhinal inputs to LEC depends either on coincident inputs from multiple sensory areas or from cortex and amygdala (Kajiwara et al., 2003; Pelletier et al., 2004; Paz et al., 2006).

\section{References}

Agster KL, Burwell RD (2009) Cortical efferents of the perirhinal, postrhinal, and entorhinal cortices of the rat. Hippocampus 19:1159-1186. CrossRef Medline

Apergis-Schoute J, Pinto A, Paré D (2007) Muscarinic control of long-range GABAergic inhibition within the rhinal cortices. J Neurosci 27: 4061-4071. CrossRef Medline

Biella G, Spaiardi P, Toselli M, de Curtis M, Gnatkovsky V (2010) Functional interactions within the parahippocampal region revealed by voltage-sensitive dye imaging in the isolated guinea pig brain. J Neurophysiol 103:725-732. CrossRef Medline

Boccara CN, Kjonigsen LJ, Hammer IM, Bjaalie JG, Leergaard TB, Witter MP 
(2015) A three-plane architectonic atlas of the rat hippocampal region. Hippocampus 25:838-857. CrossRef Medline

Bonnevie T, Dunn B, Fyhn M, Hafting T, Derdikman D, Kubie JL, Roudi Y, Moser EI, Moser MB (2013) Grid cells require excitatory drive from the hippocampus. Nat Neurosci 16:309-317. CrossRef Medline

Bucci DJ, Phillips RG, Burwell RD (2000) Contributions of postrhinal and perirhinal cortex to contextual information processing. Behav Neurosci 114:882-894. CrossRef Medline

Bucci DJ, Saddoris MP, Burwell RD (2002) Contextual fear discrimination is impaired by damage to the postrhinal or perirhinal cortex. Behav Neurosci 116:479-488. CrossRef Medline

Buhl EH, Schwerdtfeger WK, Germroth P, Singer W (1989) Combining retrograde tracing, intracellular injection, anterograde degeneration and electron microscopy to reveal synaptic links. J Neurosci Methods 29: 241-250. CrossRef Medline

Burwell RD (2000) The parahippocampal region: corticocortical connectivity. Ann N Y Acad Sci 911:25-42. CrossRef Medline

Burwell RD, Amaral DG (1998a) Cortical afferents of the perirhinal, postrhinal, and entorhinal cortices of the rat. J Comp Neurol 398: 179-205. CrossRef Medline

Burwell RD, Amaral DG (1998b) Perirhinal and postrhinal cortices of the rat: interconnectivity and connections with the entorhinal cortex. J Comp Neurol 391:293-321. CrossRef Medline

Burwell RD, Hafeman DM (2003) Positional firing properties of postrhinal cortex neurons. Neuroscience 119:577-588. CrossRef Medline

Canto CB, Witter MP (2012) Cellular properties of principal neurons in the rat entorhinal cortex: II. The medial entorhinal cortex. Hippocampus 22:1277-1299. CrossRef Medline

Canto CB, Koganezawa N, Beed P, Moser EI, Witter MP (2012) All layers of medial entorhinal cortex receive presubicular and parasubicular inputs. J Neurosci 32:17620-17631. CrossRef Medline

Cappaert NLM, Van Strien NM, Witter MP (2014) Hippocampal formation. In: The rat nervous system, Ed 4 (Paxinos G, ed). San Diego: Academic.

Colonnier M (1968) Synaptic patterns on different cell types in the different laminae of the cat visual cortex: an electron microscope study. Brain Res 9:268-287. CrossRef Medline

Couey JJ, Witoelar A, Zhang SJ, Zheng K, Ye J, Dunn B, Czajkowski R, Moser MB, Moser EI, Roudi Y, Witter MP (2013) Recurrent inhibitory circuitry as a mechanism for grid formation. Nat Neurosci 16:318-324. CrossRef Medline

Czajkowski R, Sugar J, Zhang SJ, Couey JJ, Ye J, Witter MP (2013) Superficially projecting principal neurons in layer $\mathrm{V}$ of medial entorhinal cortex in the rat receive excitatory retrosplenial input. J Neurosci 33: 15779-15792. CrossRef Medline

de Curtis M, Paré D (2004) The rhinal cortices: a wall of inhibition between the neocortex and the hippocampus. Prog Neurobiol 74:101110. CrossRef Medline

Deshmukh SS, Knierim JJ (2011) Representation of non-spatial and spatial information in the lateral entorhinal cortex. Front Behav Neurosci 5:69. CrossRef Medline

Dhillon A, Jones RS (2000) Laminar differences in recurrent excitatory transmission in the rat entorhinal cortex in vitro. Neuroscience 99: 413-422. CrossRef Medline

Dolorfo CL, Amaral DG (1998) Entorhinal cortex of the rat: organization of intrinsic connections. J Comp Neurol 398:49-82. CrossRef Medline

Eichenbaum H, Yonelinas AP, Ranganath C (2007) The medial temporal lobe and recognition memory. Annu Rev Neurosci 30:123-152. CrossRef Medline

Evers JF, Schmitt S, Sibila M, Duch C (2005) Progress in functional neuroanatomy: precise automatic geometric reconstruction of neuronal morphology from confocal image stacks. J Neurophysiol 93:2331-2342. CrossRef Medline

Furtak SC, Ahmed OJ, Burwell RD (2012) Single neuron activity and theta modulation in postrhinal cortex during visual object discrimination. Neuron 76:976-988. CrossRef Medline

Gaffan EA, Healey AN, Eacott MJ (2004) Objects and positions in visual scenes: effects of perirhinal and postrhinal cortex lesions in the rat. Behav Neurosci 118:992-1010. CrossRef Medline

Gray EG (1959) Electron microscopy of synaptic contacts on dendrite spines of the cerebral cortex. Nature 183:1592-1593. CrossRef Medline

Gundersen HJ (1986) Stereology of arbitrary particles: a review of unbiased number and size estimators and the presentation of some new ones, in memory of William R. Thompson. J Microsc 143:3-45. CrossRef Medline

Hafting T, Fyhn M, Molden S, Moser MB, Moser EI (2005) Microstructure of a spatial map in the entorhinal cortex. Nature 436:801-806. CrossRef Medline

Hargreaves EL, Rao G, Lee I, Knierim JJ (2005) Major dissociation between medial and lateral entorhinal input to dorsal hippocampus. Science 308: 1792-1794. CrossRef Medline

Jones RS (1994) Synaptic and intrinsic properties of neurons of origin of the perforant path in layer II of the rat entorhinal cortex in vitro. Hippocampus 4:335-353. CrossRef Medline

Kajiwara R, Takashima I, Mimura Y, Witter MP, Iijima T (2003) Amygdala input promotes spread of excitatory neural activity from perirhinal cortex to the entorhinal-hippocampal circuit. J Neurophysiol 89:2176-2184. CrossRef Medline

Kerr KM, Agster KL, Furtak SC, Burwell RD (2007) Functional neuroanatomy of the parahippocampal region: the lateral and medial entorhinal areas. Hippocampus 17:697-708. CrossRef Medline

Kjonigsen LJ, Lillehaug S, Bjaalie JG, Witter MP, Leergaard TB (2015) Waxholm Space atlas of the rat brain hippocampal region: three-dimensional delineations based on magnetic resonance and diffusion tensor imaging. Neuroimage 108:441-449. CrossRef Medline

Koganezawa N, Taguchi A, Tominaga T, Ohara S, Tsutsui K, Witter MP, Iijima T (2008) Significance of the deep layers of entorhinal cortex for transfer of both perirhinal and amygdala inputs to the hippocampus. Neurosci Res 61:172-181. CrossRef Medline

Kononenko NL, Witter MP (2012) Presubiculum layer III conveys retrosplenial input to the medial entorhinal cortex. Hippocampus 22:881-895. CrossRef Medline

McNaughton BL, Battaglia FP, Jensen O, Moser EI, Moser MB (2006) Path integration and the neural basis of the 'cognitive map.' Nat Rev Neurosci 7:663-678. CrossRef Medline

Moser EI, Roudi Y, Witter MP, Kentros C, Bonhoeffer T, Moser MB (2014) Grid cells and cortical representation. Nat Rev Neurosci 15:466-481. CrossRef Medline

Naber PA, Caballero-Bleda M, Jorritsma-Byham B, Witter MP (1997) Parallel input to the hippocampal memory system through peri- and postrhinal cortices. Neuroreport 8:2617-2621. CrossRef Medline

Neunuebel JP, Yoganarasimha D, Rao G, Knierim JJ (2013) Conflicts between local and global spatial frameworks dissociate neural representations of the lateral and medial entorhinal cortex. J Neurosci 33:92469258. CrossRef Medline

Norman G, Eacott MJ (2005) Dissociable effects of lesions to the perirhinal cortex and the postrhinal cortex on memory for context and objects in rats. Behav Neurosci 119:557-566. CrossRef Medline

Pastoll H, Solanka L, van Rossum MC, Nolan MF (2013) Feedback inhibition enables theta-nested gamma oscillations and grid firing fields. Neuron 77:141-154. CrossRef Medline

Paxinos G, Watson C (2007) The rat brain in stereotaxic coordinates, 6th edition. Amsterdam: Academic.

Paz R, Pelletier JG, Bauer EP, Paré D (2006) Emotional enhancement of memory via amygdala-driven facilitation of rhinal interactions. Nat Neurosci 9:1321-1329. CrossRef Medline

Pelletier JG, Apergis J, Paré D (2004) Low-probability transmission of neocortical and entorhinal impulses through the perirhinal cortex. J Neurophysiol 91:2079-2089. CrossRef Medline

Pinto A, Fuentes C, Paré D (2006) Feedforward inhibition regulates perirhinal transmission of neocortical inputs to the entorhinal cortex: ultrastructural study in guinea pigs. J Comp Neurol 495:722-734. CrossRef Medline

Ranganath C, Ritchey M (2012) Two cortical systems for memory-guided behaviour. Nat Rev Neurosci 13:713-726. CrossRef Medline

Rowland DC, Weible AP, Wickersham IR, Wu H, Mayford M, Witter MP, Kentros CG (2013) Transgenically targeted rabies virus demonstrates a major monosynaptic projection from hippocampal area CA2 to medial entorhinal layer II neurons. J Neurosci 33:14889-14898. CrossRef Medline

Sargolini F, Fyhn M, Hafting T, McNaughton BL, Witter MP, Moser MB, Moser EI (2006) Conjunctive representation of position, direction, and velocity in entorhinal cortex. Science 312:758-762. CrossRef Medline

Schmitt S, Evers JF, Duch C, Scholz M, Obermayer K (2004) New methods for the computer-assisted 3-D reconstruction of neurons from confocal image stacks. Neuroimage 23:1283-1298. CrossRef Medline 
Solstad T, Boccara CN, Kropff E, Moser MB, Moser EI (2008) Representation of geometric borders in the entorhinal cortex. Science 322: 1865-1868. CrossRef Medline

Tolner EA, Frahm C, Metzger R, Gorter JA, Witte OW, Lopes da Silva FH, Heinemann U (2007) Synaptic responses in superficial layers of medial entorhinal cortex from rats with kainate-induced epilepsy. Neurobiol Dis 26:419-438. CrossRef Medline

Tominaga T, Tominaga Y, Yamada H, Matsumoto G, Ichikawa M (2000) Quantification of optical signals with electrophysiological signals in neural activities of Di-4-ANEPPS stained rat hippocampal slices. J Neurosci Methods 102:11-23. CrossRef Medline

Uchizono K (1965) Characteristics of excitatory and inhibitory synapses in the central nervous system of the cat. Nature 207:642-643. CrossRef Medline

Witter MP, Chan-Palay V, Kohler C (1989) Connectivity of the rat hippocampus. In: The hippocampus-new vistas, pp 53-69. New York: Allen R. Liss.

Witter MP, Wouterlood FG, Naber PA, Van Haeften T (2000) Anatomical organization of the parahippocampal-hippocampal network. Ann N Y Acad Sci 911:1-24. CrossRef Medline

Witter MP, Canto CB, Couey JJ, Koganezawa N, O’Reilly KC (2014) Architecture of spatial circuits in the hippocampal region. Philos Trans R Soc Lond B Biol Sci 369:20120515. CrossRef Medline
Wouterlood FG, Van Haeften T, Eijkhoudt M, Baks-Te-Bulte L, Goede PH, Witter MP (2004) Input from the presubiculum to dendrites of layer-V neurons of the medial entorhinal cortex of the rat. Brain Res 1013:1-12. CrossRef Medline

Wouterlood FG, Boekel AJ, Kajiwara R, Beliën JA (2008) Counting contacts between neurons in $3 \mathrm{D}$ in confocal laser scanning images. J Neurosci Methods 171:296-308. CrossRef Medline

Yoganarasimha D, Rao G, Knierim JJ (2011) Lateral entorhinal neurons are not spatially selective in cue-rich environments. Hippocampus 21: 1363-1374. CrossRef Medline

Young BJ, Otto T, Fox GD, Eichenbaum H (1997) Memory representation within the parahippocampal region. J Neurosci 17:5183-5195. Medline

Zhang SJ, Ye J, Couey JJ, Witter M, Moser EI, Moser MB (2014) Functional connectivity of the entorhinal-hippocampal space circuit. Philos Trans R Soc Lond B Biol Sci 369:20120516. CrossRef Medline

Zhu XO, Brown MW (1995) Changes in neuronal activity related to the repetition and relative familiarity of visual stimuli in rhinal and adjacent cortex of the anaesthetised rat. Brain Res 689:101-110. CrossRef Medline

Zhu XO, Brown MW, Aggleton JP (1995) Neuronal signalling of information important to visual recognition memory in rat rhinal and neighbouring cortices. Eur J Neurosci 7:753-765. CrossRef Medline 